\title{
Principles of work of different types of underwater breathing apparatus
}

\author{
Ryszard Kłos, Assoc. Prof. \\ Polish Naval Academy
}

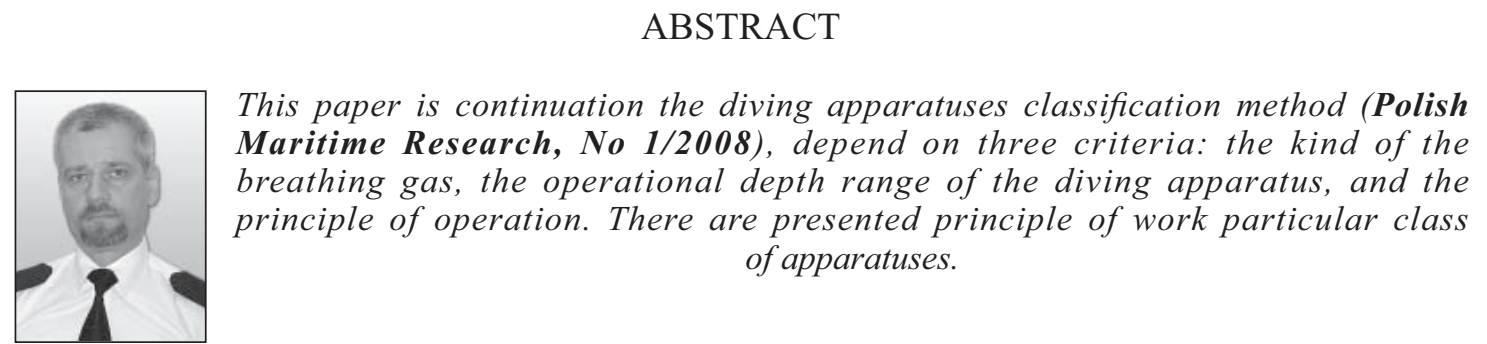

Keywords: diving apparatus, principle of work

\section{INTRODUCTION}

Design of underwater breathing apparatus is determined primarily by type of circuit of the breathing medium, hence discussed here are the principles of operation of general types of engineering solutions (not of any model in particular), according to following division:

- open circuit apparatus

- semi-closed circuit apparatus

- closed circuit apparatus.

\section{METHODS}

\section{Open circuit $U B A$}

Open circuit UBA is basically known as air breathing apparatus. Engineering variations of this type of apparatus are many. Apart into hose and SCUBA types they can be also divided according to number of stages of pressure reduction to be obtained at the demand valve:

- single-stage pressure reduction regulator

- two-stage pressure reduction regulator.

Systems of a higher number of pressure reduction stages are not met (although, installation of the so called pilot valves is claimed to serve as an additional reduction stage by some). The two-stage reduction systems may be divided into:

A designs with separated stages of reduction

A designs with combined stages of reduction.
Recommended for diving works is hose apparatus with two-stages pressure reduction. Regardless of the type of the automatic pressure reduction allowing for the ambient depth of diving, general principle of the open circuit apparatus is similar. It has been generally displayed in Fig. 1 (demand valve of two separate pressure reduction stages).

SCUBA (used as escaping apparatus) consits exclusively of the B equipment as marked in the Fig. 1. In its version with hose it contains additionally external supply unit A and supply line $\mathrm{C}$. The major interest of the construction of UBA is the demand valve which reduces the pressure in the supply hose (or in integral set of pressure cylinders 15 ) to the ambient pressure of the diving depth. The demand system is divided into:

+ water space 4 with the escape valve 5

+ gaseous area 7 containing the pressure reduction unit 8 (second stage of pressure reduction)

+ first stage of pressure reduction unit 10 (for self-contained version).

First stage reduction unit 10 (for SCUBA) is controlled by the hydrostatic pressure via the diaphragm it cooperates with. Thanks to it the breathing medium remains under a constant overpressure in relation to the hydrostatic pressure of a given diving depth. The reduction unit of the second stage 8 is controlled by hydrostatic pressure via the diaphragm 6 . As a result it can deliver the breathing medium into the diver's lungs at a pressure equal to the hydrostatic pressure on the depth of diving. In order to diminish the inhalation resistance this unit is often equipped with a device aiding suction (not shown in 


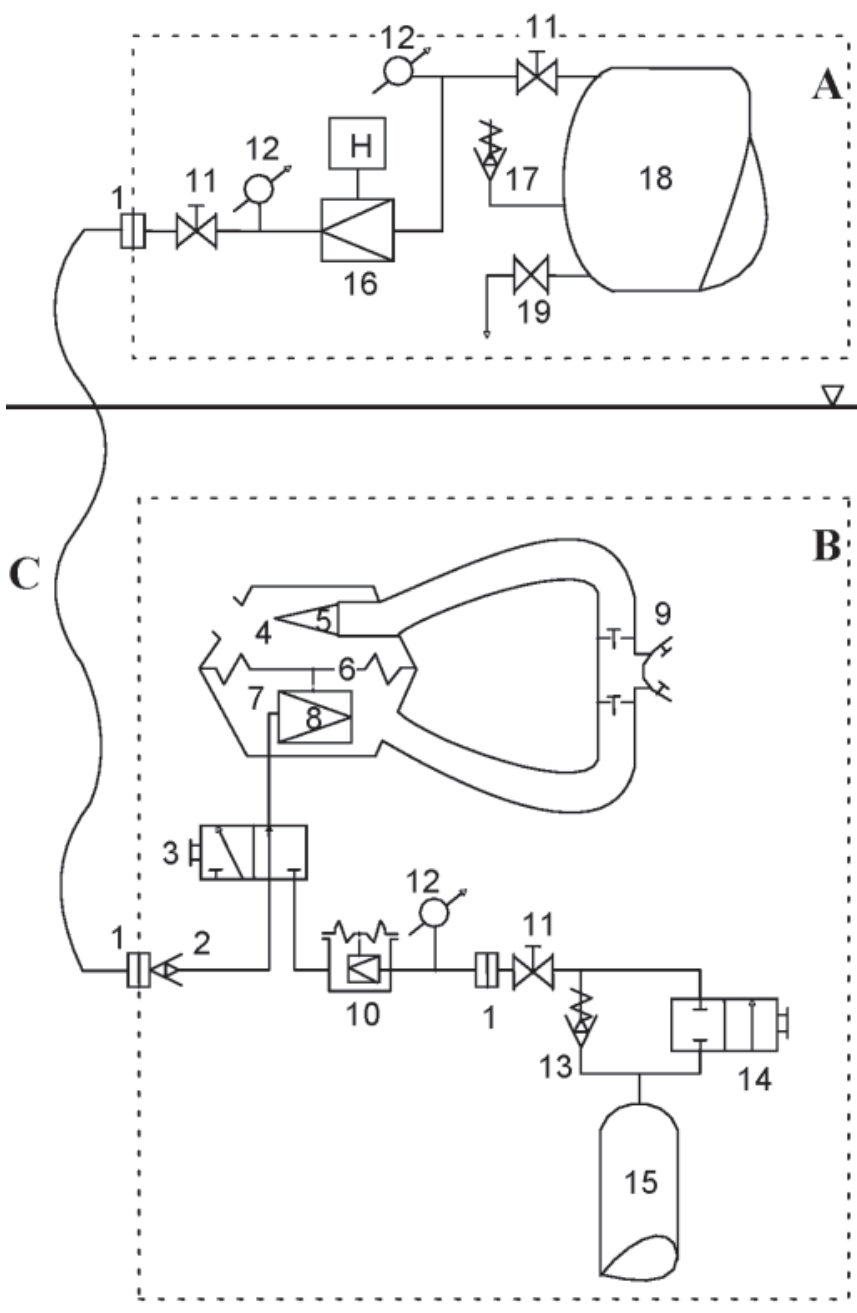

Fig. 1. Open circuit UBA. A. External supply of hose version UBA with open circuit of breathing medium. B. SCUBA with open circuit of breathing medium. $\boldsymbol{C}$. Supply line. 1) function, 2) non-return valve, 3) selector valve, 4) water space of demand valve, 5) non-return escape valve, 6) diaphragm,

7) gaseous space of demand valve, 8) unit of breathing medium pressure reduction cooperating with the diaphragm - second stage pressure reduction (second stage regulator), 9) mouthpiece device with valves and hoses, 10) reducer holding overpressure of breathing medium constant relative to hydrostatic pressure (first stage pressure reduction - first stage regulator), 11) cut-off valve, 12) manometer, 13) throttle-stop valve of the reserve unit, 14) valve actuating reserve of the breathing medium, 15) unit self-contained holders, 16) manually controlled reducer, 17) safety valve, 18) external holders with the breathing medium stored, 19) drainage valve the Fig. 1). As to ensure emergency supply of the breathing gas the external supply unit should also include reserve holders. For self-contained version cylinders set 15 should also have pressure valve of the breathing medium reserve marked in the Fig. 1 as 13. During regular work the diver receives breathing medium from the external supply unit A (distribution valve 3 is set as indicated in the Fig. 1, the valve 11 from the autonomous cylinder set 15 , open).

It is recommended for the breathing medium to be administered at a pressure preliminary reduced (reducer 16), but allowing for a proper work of the second stage of the demand valve. Owing to it, the hoses resistant to lower pressure may be used. The self-contained cylinders set 15 together with its software when cut off with the distribution valve 3 serves as emergency reserve of the breathing medium. The moment the breathing medium from the external supply unit has been cut off, the user switches the valve 3 triggering autonomous supply. The reserve of the breathing medium should be sufficient to let the diver leave the working site safely and his surfacing or reaching a safe place (e.g.: diving bell).

The circuit of the breathing gas at work with external supply is a simplified version of what happens to it at SCUBA; hence it is discussed taking the latter case as a model. During a regular work of SCUBA version the reserve valve 14 (in position as in Fig. 1) is shut.

From the cylinder set 15 the breathing medium is pushed through the throttle-stop valve of the reserve device 13, through the first reduction stage 10 to the reduction unit of the demand valve 8 (the selector valve 3 is now positioned differently than shown in the Fig. 1) where from, through a hose, the inhale valve and a mouthpiece device 9 right into the diver's lungs. Than, from the lungs through the exhale valve of the mouthpiece, hose and non-return escape valve 5 , through the water section of the demand valve 4 into the water. The moment the pressure in the cylinders set 15 has fallen to the value at which the valve 13 gets cut off, the diver feels the inhalation resistance rising, and then short of the breathing medium. This is a signal that the reserve of the breathing medium (indicated by the manufacturer of the apparatus) has been cut off. To trigger this supply the user must switch the reserve valve 14. Description of the types of open circuit apparatus is presented in Table 4. Examples of the open circuit apparatuses detailed in Table 3 are shown in Photos $12 \div 17$.

Table 4. Basic features of open circuit UBA

\section{Open circuit UBA}

This type diving apparatus is known primarily as air UBA. For recreational and sports purposes most commonly used in self-contained (SCUBA), air version. For commercial diving recommended exclusively is the hose version with two, separate-stage pressure reduction regulator.

\begin{tabular}{|l|l|}
\hline \multirow{5}{*}{ Disadvantages: } & $\begin{array}{l}\text { - Limited maximum diving depth (at air as breathing medium) not allowing for the continental shelf } \\
\text { - At artificial breathing media the system unacceptable out of economic considerations, at helium } \\
\text { mixtures, in particular. } \\
\text { - Relatively short time of protective action of the autonomous version, and at air as breathing gas also } \\
\text { long decompression time and long time needed for relaxation afterwards. } \\
\text { - Complicated construction of the regulators (comparing to technical other solutions) affecting reliability } \\
\text { of operation and imposing requirement of specialistic qualified personnel. }\end{array}$ \\
\hline Advantages: & $\begin{array}{l}\text { - The breathing medium used does not get mixed with the fresh one. } \\
\text { - Unexpensive and readily available breathing medium in the air is used. } \\
\text { - Diving depth, at the air as breathing medium, sufficient to carry out harbour underwater works, } \\
\text { protection against damages to ships, and at majority works involved in the maintenance of hydro- } \\
\text { engineering objects. }\end{array}$ \\
\hline
\end{tabular}




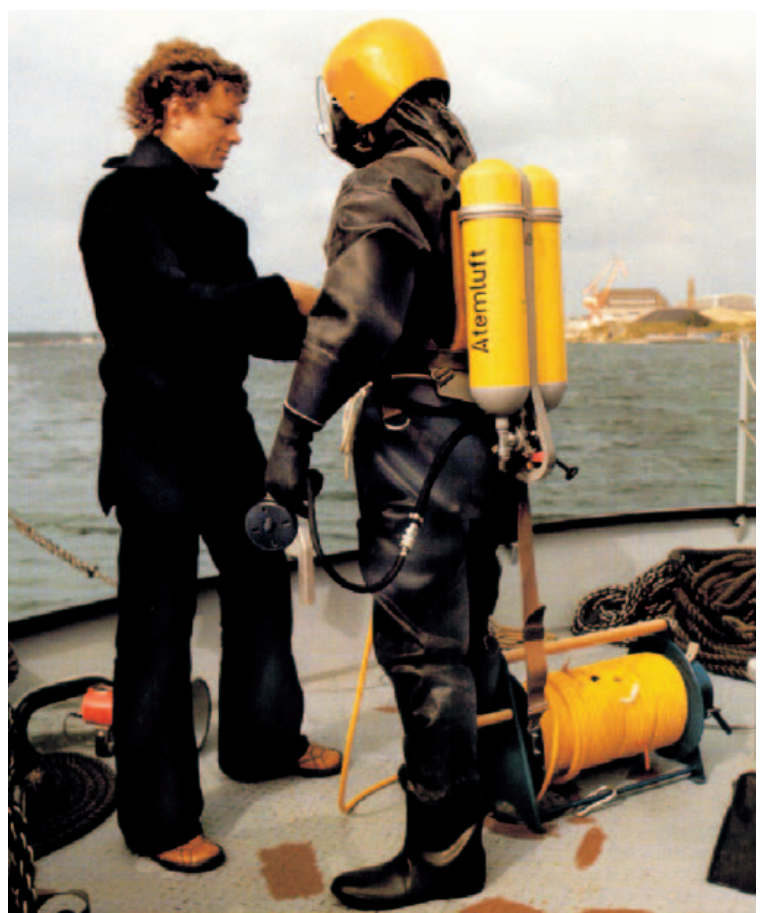

Photo 12. PA-38/3600 type SCUBA

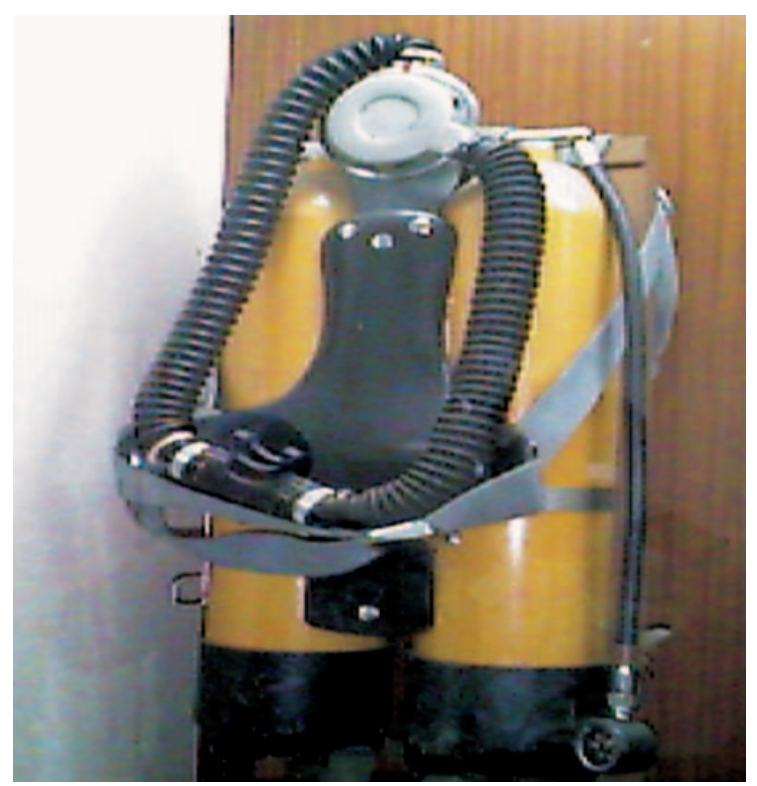

Photo 13. Diving apparatus PR-27 type SCUBA

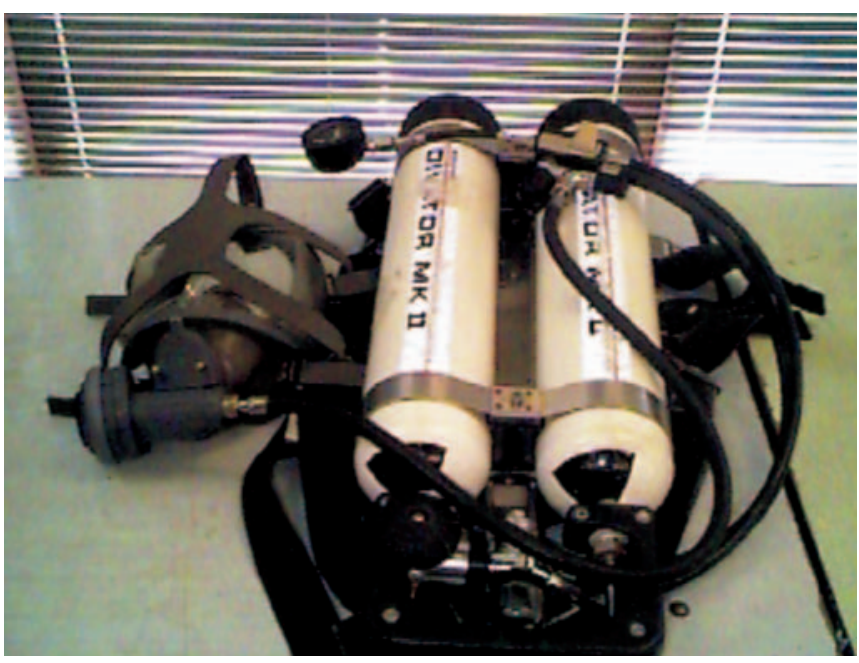

Photo 14. AGA Mk II SCUBA

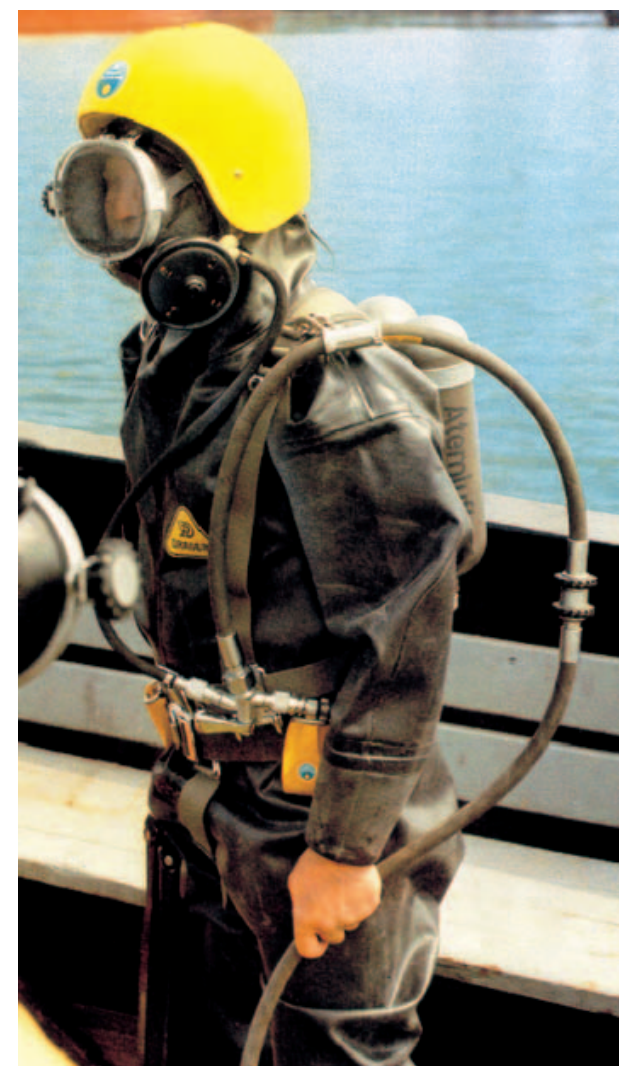

Photo 15. PL-70 UBA

\section{SEMI-CLOSED CIRCUIT OF BREATHING MEDIUM UBA (SCR)}

In UBA with semi-closed (semi-pen) circuit of breathing medium (SCR) exclusively artificial breathing media are used:

$\star$ SCR using ready breathing medium (premix-SCR)

$\star$ SCR producing breathing medium during diving (automix-SCR)

The automix SCR offers possibility of:

* producing breathing medium during diving at a constant ratio of content of oxygen and inert gases

* producing breathing medium during diving at changeable ratio of content between oxygen and inert gases according to depth.

Taking mode of supply as division criterion we can distinguish between:

* self-contained SCR (SC-SCR)

* external (hose) supply SCR.

In SCR the role of system supplying breathing medium under the ambient pressure of diving depth has been taken over by elastic bags or breathing bellows. In this aspect SCR can be into designs equipped with:

* one-bag SCR

two-bags SCR.

Any bigger number of bags is seldom to be met. Again, considering the mutual arrangement of the bags, the two-bags can be classified into designs with:

is separate-bags

is one bag contained in the other.

Characteristic for diving systems which use premix is that they administer breathing gas at constant volume or actuated to the breathing rhythm of the user. The technical design of the metering device allows grouping them as follows: 
- SCR with nozzle reduction-metering system

SCR taking advantage of evacuation of the metering cylinder

SCR with system of breathing gas metering by means of set of bags arranged one in the other.

The classification of various technical designs of SCR in regard of the breathing bags construction is contained in Table 5.

\section{Premix-SCR}

General principle of two-bag premix-SCR (separate bags) with nozzle reductive-metering system is shown in Fig. 2 . The SC-SCR part of one-bag SCR is illustrated in Fig. 3. Their principles of work being so much alike it is the SCR presented in Fig. 2 that will be discussed in details. When discussing the principles of operation of the SCRs term "metering" will be used, i.e. mass flow per time unit passing through the bore of a nozzle of SCR.

The part which is crossed and marked as B represents SCUBA version of SCR. Again, connecting the parts A and B with supply hose $\mathrm{C}$ creates hose supply SCR version (houseSCR), where breathing gas supply stored in unit 15 is emergency (escape) supply. In hose-SCR version gas from the cylinder 17 is passed via reducer 12 and selector valve 4, metering nozzle 11 , inner supply unit into supply hose C. Through supply unit, return valve 2 , valve selecting mode of supply 3 , into inhalation bag 10 . In the autonomous version breathing medium from the unit of cylinders 15 passes through cut-off valve 14 and manometric pressure control 13 to finally reach reductor 12 . Then through the selector valve 3 (set differently than show in the Fig. 2) and the nozzle 11, which was selected with nozzles selector valve 4 , into the breathing bag 10 . Breathing bags are made of an elastic, gas-tight fabric, therefore the pressure in the bags approximates summaric value of the ambient hydrostatic pressure at the given depth and the overpressure opening relief valve (certain fluctuations of the pressure in the breathing area should be expected according to the positioning the apparatus on the diver's body and his very position in the water). The breathing medium from the inhalation bag 10 is lost through the hose and inhalation valve of the mouthpiece device 9 into

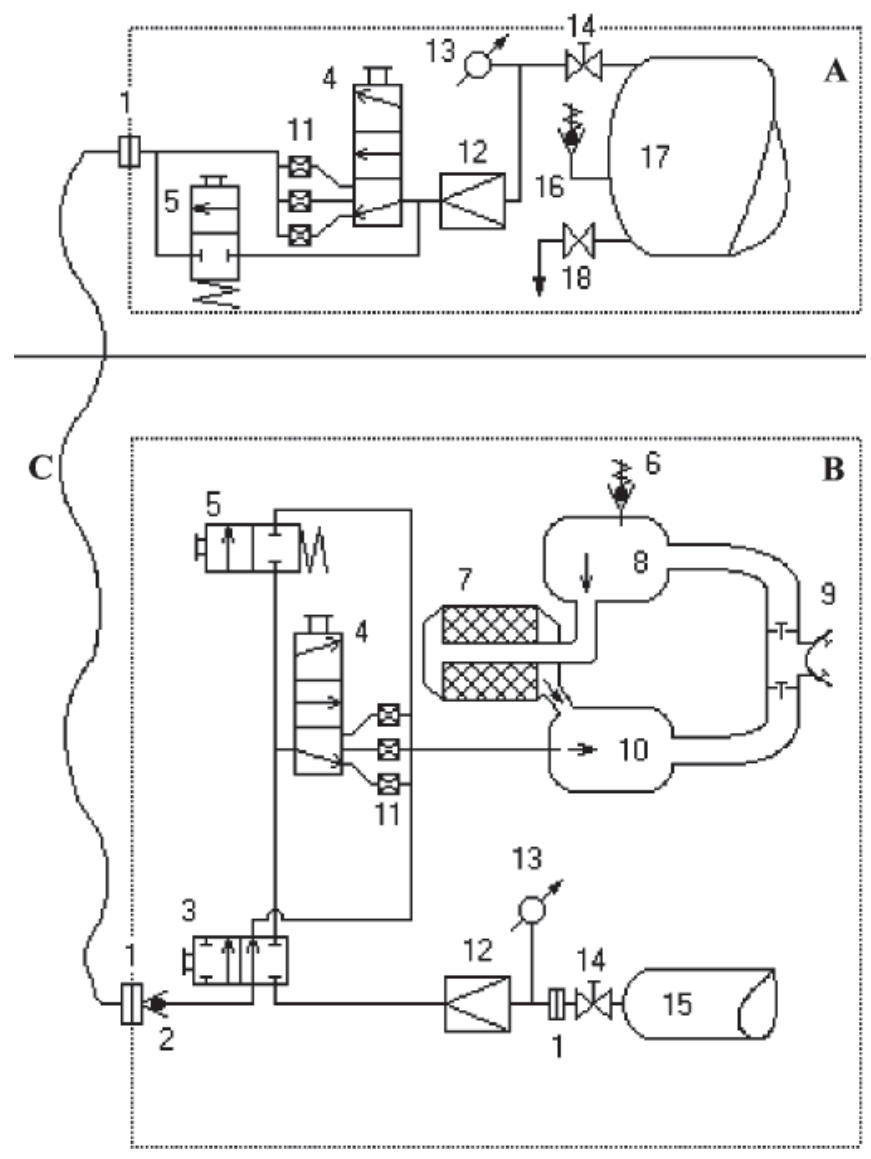

Fig. 2. Two-bag version of the premixSCR. A. External supply unit of hose version of premix-SCR, B. SC-premix-SCR, C. Supply hose, 1) coupling, 2) return valve, 3) supply mode selector valve, 4) metering nozzles selector valve, 5) by-pass valve, 6) relief valve, 7) carbon dioxide absorbent, 8) exhalation bag, 9) mouthpiece device with valves and hoses, 10) inhalation bag, 11) metering nozzles, 12) reducer, 13) manometer 14) cut-off valve, 15) autonomous set of cylinders, 16) safety valve, 17) external cylinders with breathing medium stored, 18) drainer valve

the diver's lungs. Exhalation runs through exhalation valve and exhalation hose into exhalation bag 8 , wherefrom the breathed out gas passes into carbon dioxide absorbent 7 . The relief

Table 5. Classification of SCRs in view of type of construction of the breathing bags

\begin{tabular}{|l|l|l|}
\hline \multicolumn{2}{|l|}{ One-bag SCR } & \multicolumn{1}{c|}{ Classification of SCR } \\
\hline \multirow{2}{*}{ with separate bags } & \multicolumn{1}{c|}{ Two-bag SCR } \\
\hline \multirow{5}{*}{ Disadvantages: } & $\begin{array}{l}\text { - In one-breathing-bag SCR breathing medium designed for rebreathing is partly lost. } \\
\text { - All the designs are less hygienic than the open circuit of breathing medium due to partly closing of } \\
\text { the breathing medium circuit. } \\
\text { - All constructions of SCR are less economical in use than diving apparatus of closed circuit of } \\
\text { breathing medium. } \\
\text { - The complex construction of breathing bags in SCR with the bags one in the other may result in less } \\
\text { reliability of the device. }\end{array}$ \\
\hline Advantages: & $\begin{array}{l}\text { - In two-breathing-bag solution the losses to come about involve only the breathing medium which has } \\
\text { not been purified from carbon dioxide, thus economizing on filling of the absorbent and prolonges } \\
\text { duration of its protective action (vital for the hose version). } \\
\text { - In the SCR with separate bags it is easier to arrange the bags in the casing, making the whole unit } \\
\text { more compact. } \\
\text { - With the SCR with bags contained one in the other, we are able to precisely determine the ratio } \\
\text { between the amount of the breathing medium removed and the total amount of this medium in the } \\
\text { circuit. Metering the breathing gas is carried out on periodical basis and adjusted to the breathing } \\
\text { rhythm of the diver. To set the overpressure of opening the relief valve for this type apparatus turns } \\
\text { less important than for other systems with semi-closed circuit of the breathing medium. }\end{array}$ \\
\hline
\end{tabular}


valve 6 which is mounted on exhalation bag is meant to lose the excess of the exhaled gas into the water.

The expired medium running through the absorbent gets purified from carbon dioxide and joins the clean breathing medium circuit entering inspiration bag 10 , mixing here with fresh breathing medium. Worth of notice, the value of the reduced pressure of breathing medium should remain at a level permitting the selected nozzle to work within the range of its supercritical flows, maintaining it for the whole of the diving depths allowed, what means that its mass expenditure is kept at a constant level with an assumed tolerance.

This type of hose supply premix SCR is equipped with special by pass valves 5 , designed for filling and washout

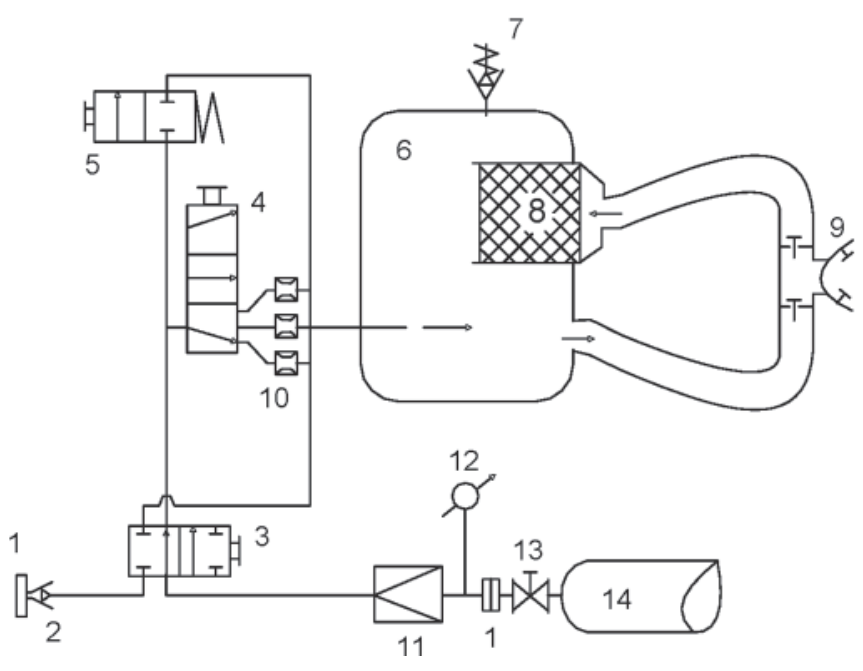

Fig. 3. One-bag SC-premix-SCR. 1) coupling, 2) return valve, 3) selector valve, 4) selector valve of metering nozzles, 5) by pass valve, 6) breathing bag, 7) relief valve, 8) carbon dioxide absorbent, 9) mouthpiece unit with valves and hoses, 10) metering nozzles, 11) reducer, 12) manometer, 13) cut-off valve, 14) autonomous set of cylinders (ventilation) of the breathing area. In the hose supply SCR version, by-pass valve (for the design described above) is steered by an external supply A team - holding intercourse with the diver by means of technical aids. A basic feature of premix SCR is contained in Table 6. Apart from the nozzle metering system, the other solutions are also to be met. They operate on principle that ventilation of the diver's lungs is the function of the oxygen stream consumed. The solution applied in Swedish ACSC type SC-SCR (Alternatively Closed/Semiclosed Demand Breathing Apparatus - Photo 19) lies in evacuation of the special metering cylinder. In French FENZY-68 type SC-SCR (Photo 23) and DC-55 (Photo 24) metering of fresh breathing medium is regulated by set of bags contained one in the other.

Metering system performed by evacuation of the metering cylinder is presented in Fig. 4. Every slight movement of the breathing bellow 1 induced by breathing is counted by the pawl mechanism of the system regulating the metering valves 2 . Filling and evacuation of the metering cylinder 4 is carried out by switching valve 3 by the steering system 2 .

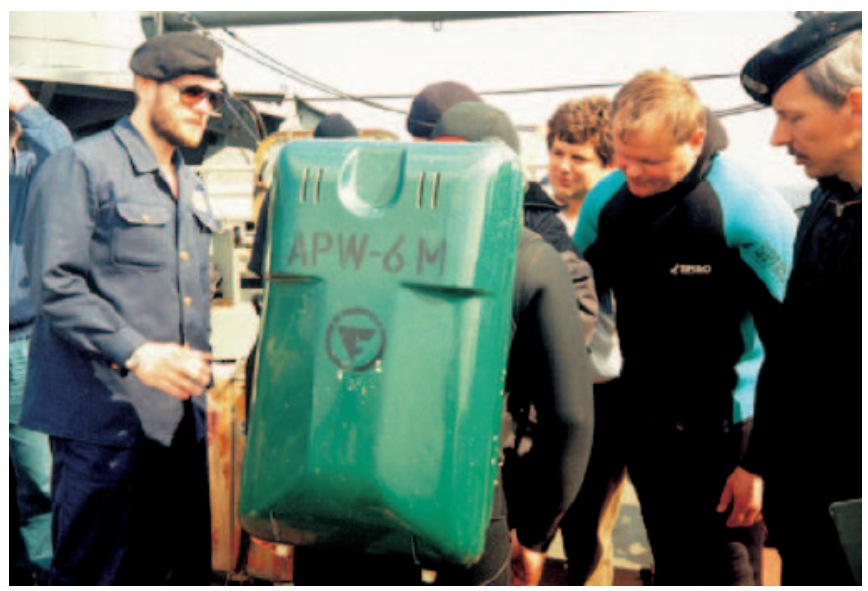

Photo 18. SC-premix-SCR APW-6M type

Table 6. Characteristic of premix SCR

\begin{tabular}{|c|c|}
\hline \multicolumn{2}{|c|}{ Apparatus of semi-closed circuit of ready breathing medium (Premix SCR) } \\
\hline \multicolumn{2}{|c|}{ Premix SCR is known as system designed for gas mixtures as breathing medium (oxygen is possible). } \\
Among the breathing media used most frequently one may find the mixtures: helium-oxygen (Heliox), \\
\hline \\
- The choice of breathing medium as to its composition and metering confined to \\
a relatively narrow range of depth. \\
- Relatively complicated preparation of apparatus for work (preparing breathing mixture, checking its \\
composition, checking correctness of the absorbent's filling, checking metering and positioning of the \\
relief valve, checking leak tightness etc.). \\
- Technical difficulties resulting from a proloned storing of the breathing medium (likehood of \\
stratification of the components, with helium-oxygen mixtures, in particular).
\end{tabular}




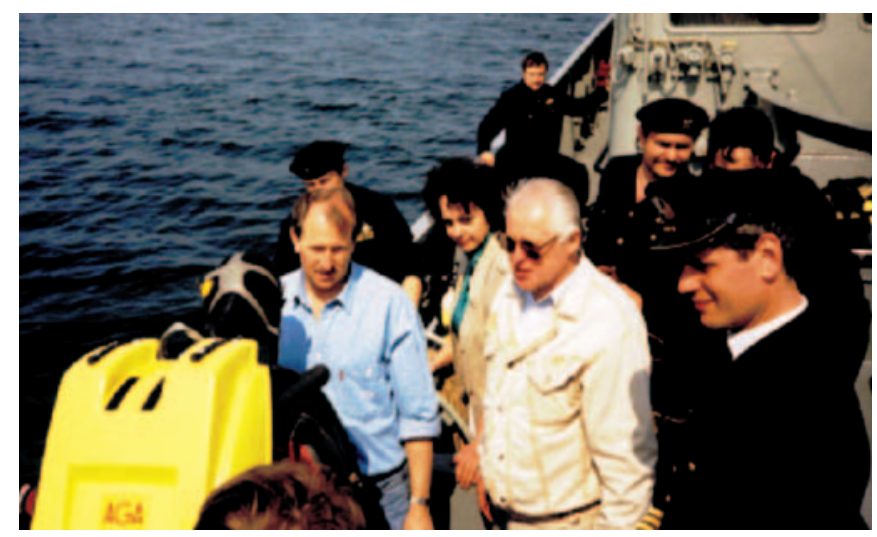

Photo 19. SC-premix-SCR ACSC type

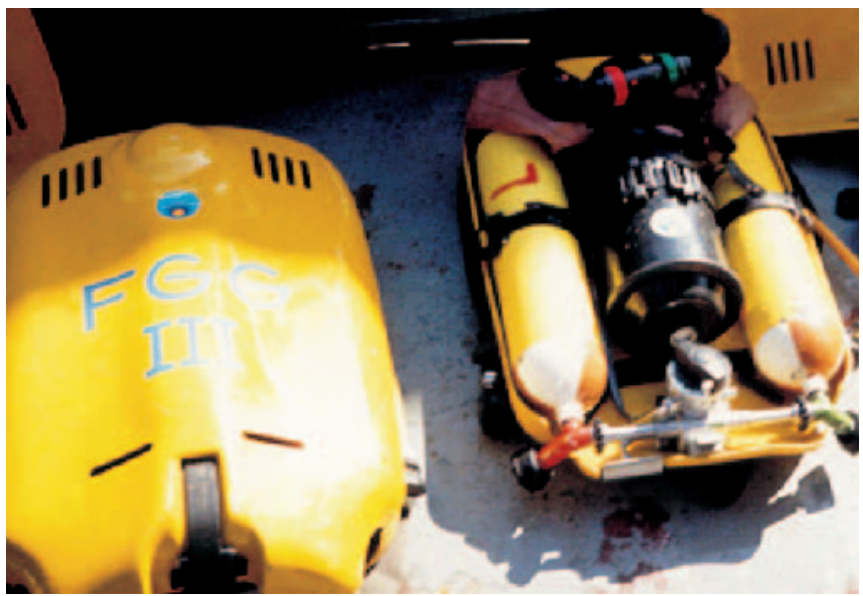

Photo 20. Premix house-premix-SCR FGG III type

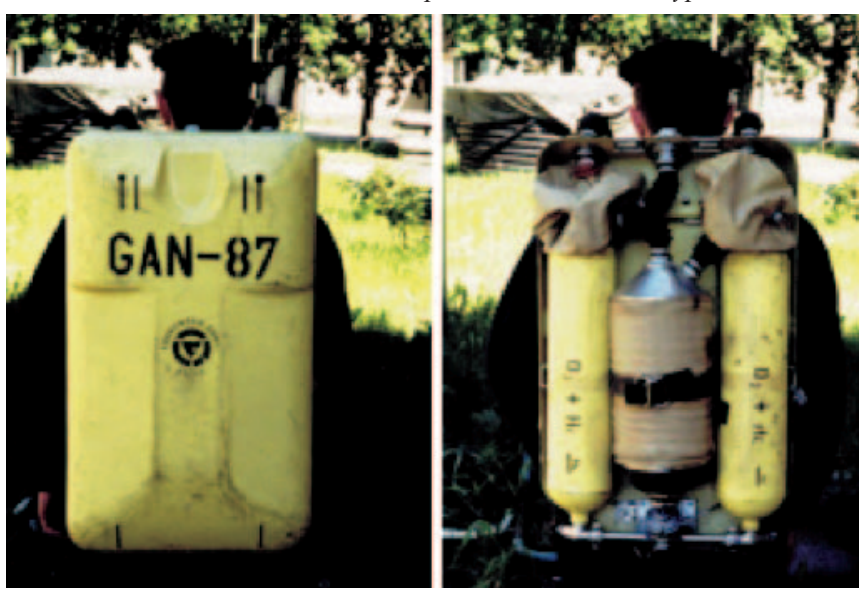

Photo 21. Premix house-premix-SCR GAN-87 type

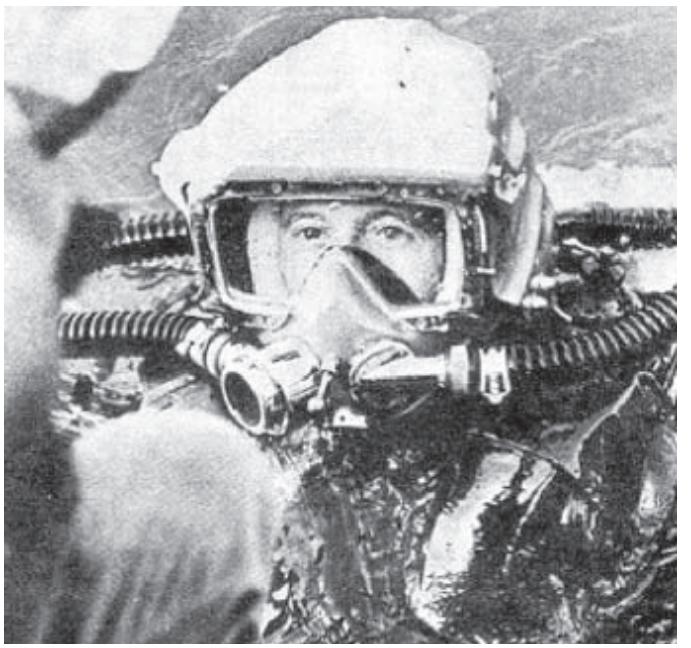

Photo 22. SCR applied in SealabIII [4]

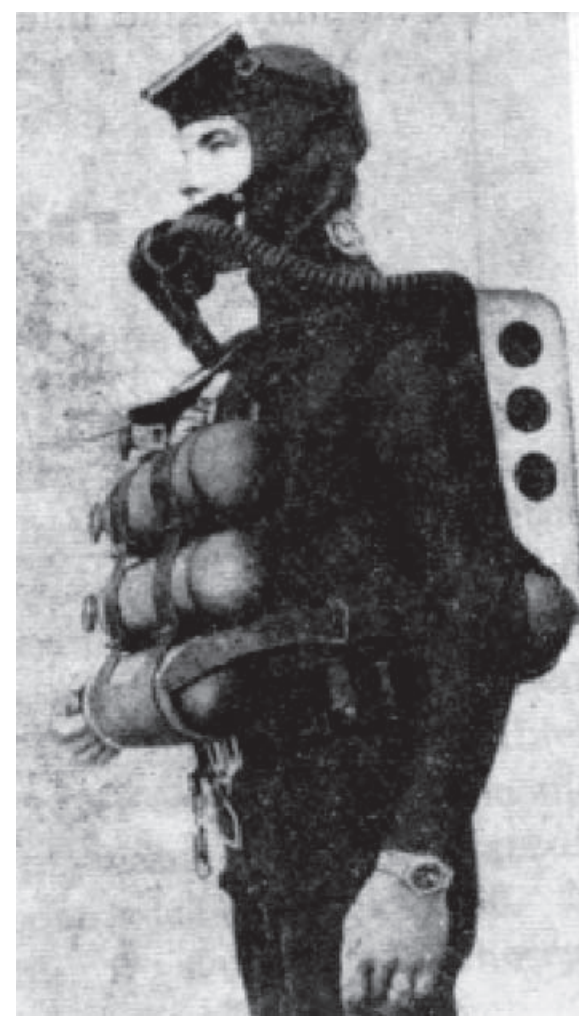

Photo 23. SC-premix-SCR Fenzy-68 type [4]
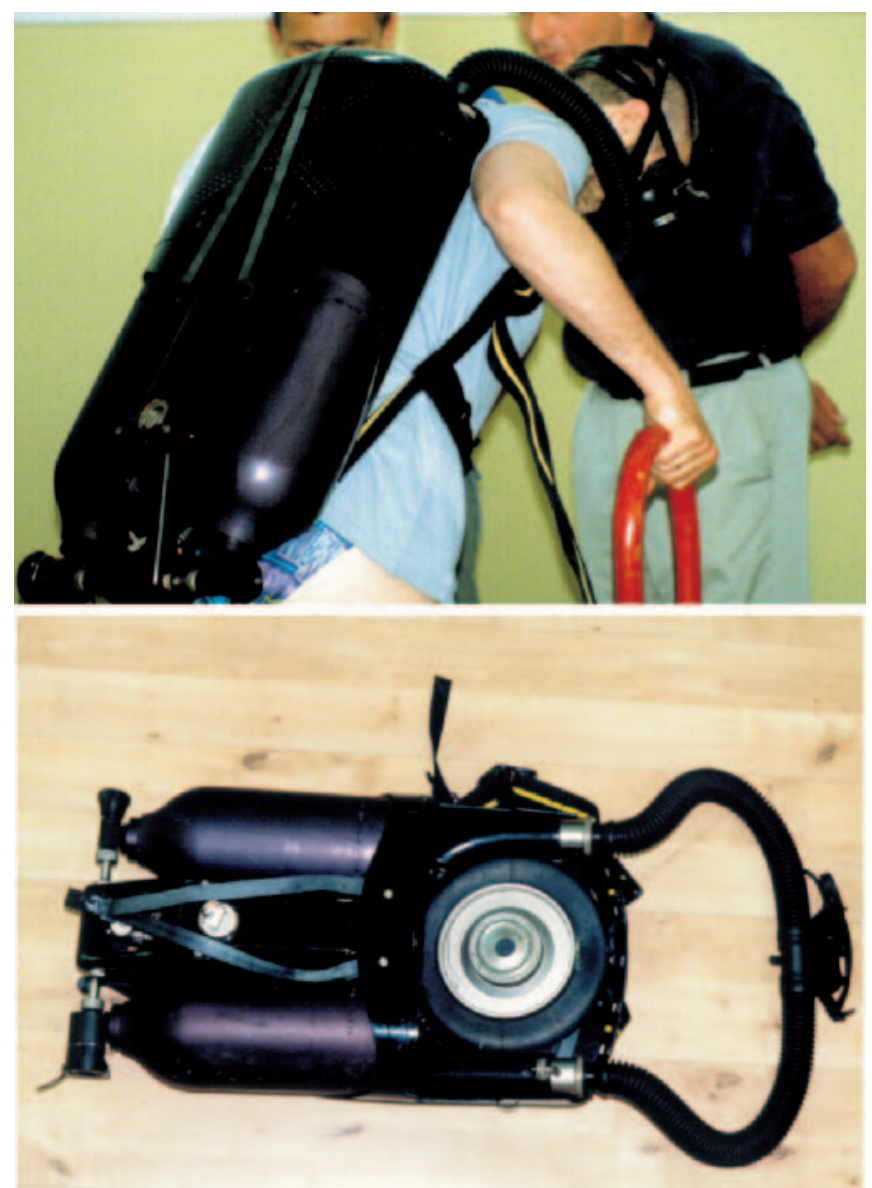

Photo 24. SC-premix-SCR DC-55 type

In Fig. 4 the valves 3 are shown in position of evacuation of the metering cylinder 4 . To maintain the constant mass rate of the fresh medium metered, the supply overpressure of the cylinder 4 is kept at a constant level by the pressure reducer 5 . This system can sense the outer pressure via an 


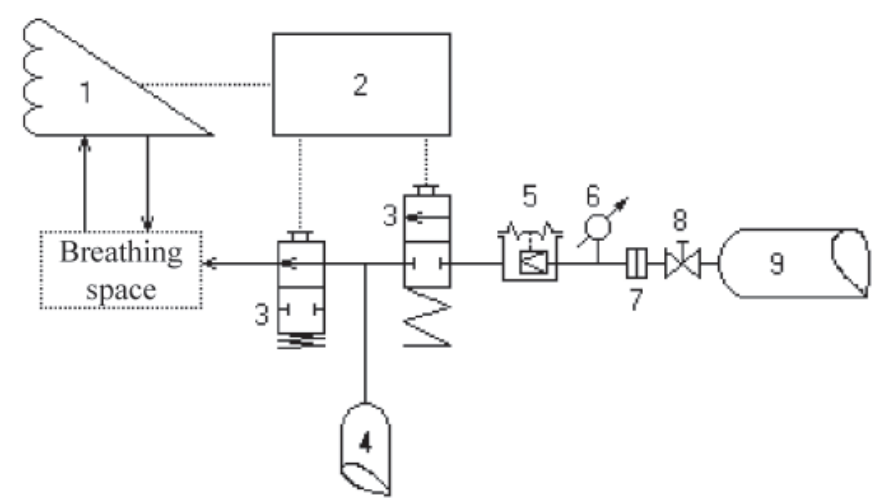

Fig. 4. Metering system in the premix-SCR taking advantage of evacuation of a constant capacity holder and constant over-pressure of loading. 1) breathing bellow, 2) system regulating metering valves, 3) metering valves, 4) metering cylinder, 5) reducer maintaining constant overpressure of breathing medium supply relative to ambient pressure, 6) manometer, 7) coupling, 8) valve, 9) supply cylinder

elastic diaphragm. When the sum of the bellow's motions achieves the certain definite number valves 3 get switched and the content of the cylinder 4 is then forced through into the breathing space of SCR. This solution gives the possibility of economical management of the fresh breathing gas stock, as its metering is carried out on demand due breathing rate. It also allows for a precise development of decompression procedures, as any changes in the composition of the breathing medium are only in a slight degree dependent on the actual exertion input of the diver. For the designs with a constant metering of fresh breathing medium this relationship is much more distinct. ACSC apparatus is equipped with a number of very complicated mechanical safety devices, among them: emergency supply of breathing medium, a device preventing from subsidence of breathing bellow during a rapid submersion etc. For this reason it turns a very complicated and a delicate design, first costs and operating costs are high. This apparatus is know only in nitrox version, although there have been undertaken several attmepts to use it at deep diving as well. This type of SCR is employed exclusively for military purposes oading operations. It is an element of mine clearance diving system. In this aim it is made of non-magnetic material and is equipped with a device diffusing breathing medium released through the relief valve into the water.

In French SCRs FENZY-68 and DC-55 metering of the fresh breathing medium is solved by means of a special unit of bellows (bags) arranged one in the other (Fig. 5). When discussing operating priniciples of this system one must make a clear distinction between exhale and inhale phase. One-way circuit of the breathing medium is maintained with non-return valves 1 . During exhale phase (Fig. 5a) escape valve of the mouthpiece device gets open. The exhaled gas is let through the mouthpiece 12, exhale hose and escape valve into $\mathrm{CO}_{2}$ absorbent 11 and then to the large bag 2, therefrom, via nonreturn valve into the small bag 3. On inhalation (Fig. 5b), escape valve is closed. In turn, the inhale valve opens. From the large bag 2 the breathing medium is issued into the lungsthrough the inhale valve, inhale hose and mouthpiece device 12. On inspiration the capacity of the bag 2 diminishes. When collapsing the large bag 2 is pressing the metering valve 5 lever triggering it. It causes the fresh breathing gas from the cylinder 10 to flow passing the cut-off valve 9, coupling 8 , reducer 6 and metering valve 5 , into the large bag 2 to get mixed with the recycled breathing medium. And now via nonreturn valve, breathing hose and the mouthpiece device 12 right into the lungs. This solution is very economical because breathing medium is administered on demand, actuated by the breathing action and the capacity relation between the large and the small bags.
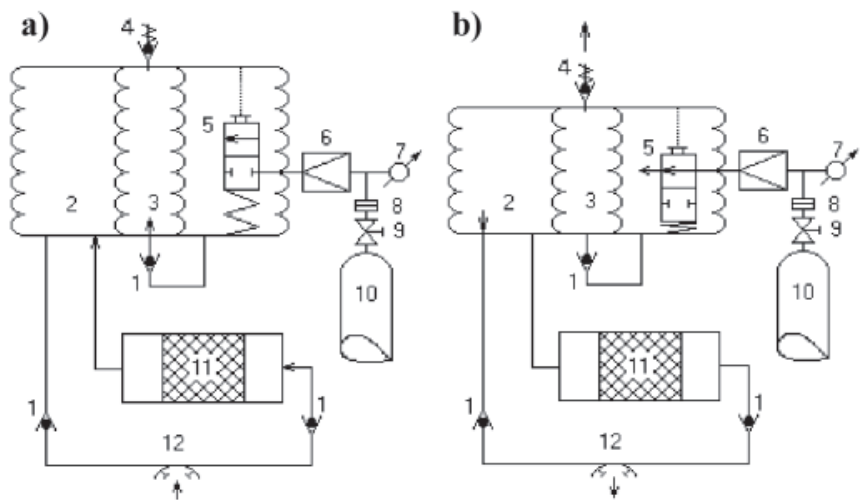

Fig. 5. Engineering principles of SCR, with breathing bags arranged one in the other. $\boldsymbol{A}$. Exhalation phase, $\boldsymbol{B}$. Inhalation phase, 1) non-return valve, 2) large bag (outer), 3) small bag (inner), 4) relief valve, 5) metering valve, 6) reducer, 7) manometer, 8) coupling, 9) valve, 10) cylinder with breathing medium, 11) $\mathrm{CO}_{2}$ absorbent canister, 12) mouthpiece device

Such a system however, does not provide a sufficient metering at larger diving depths. For this reason at depths greater than $25 \mathrm{~m}$ it must be supported by a nozzle system of constant metering. SCRs FENZY-68 and DC-55 type are as much as ACSC are used only in the navy, in nitrox version to about $50 \mathrm{~m} \mathrm{H}_{2} \mathrm{O}$.

\section{Automix-SCR}

Operation principle of one-bag breathing automix-SCR is illustrated in Fig. 6. The system produces breathing medium characterised by a constant ratio of contents between oxygen and inert gases. Designs of this type (Fig. 6) in hose-SCR

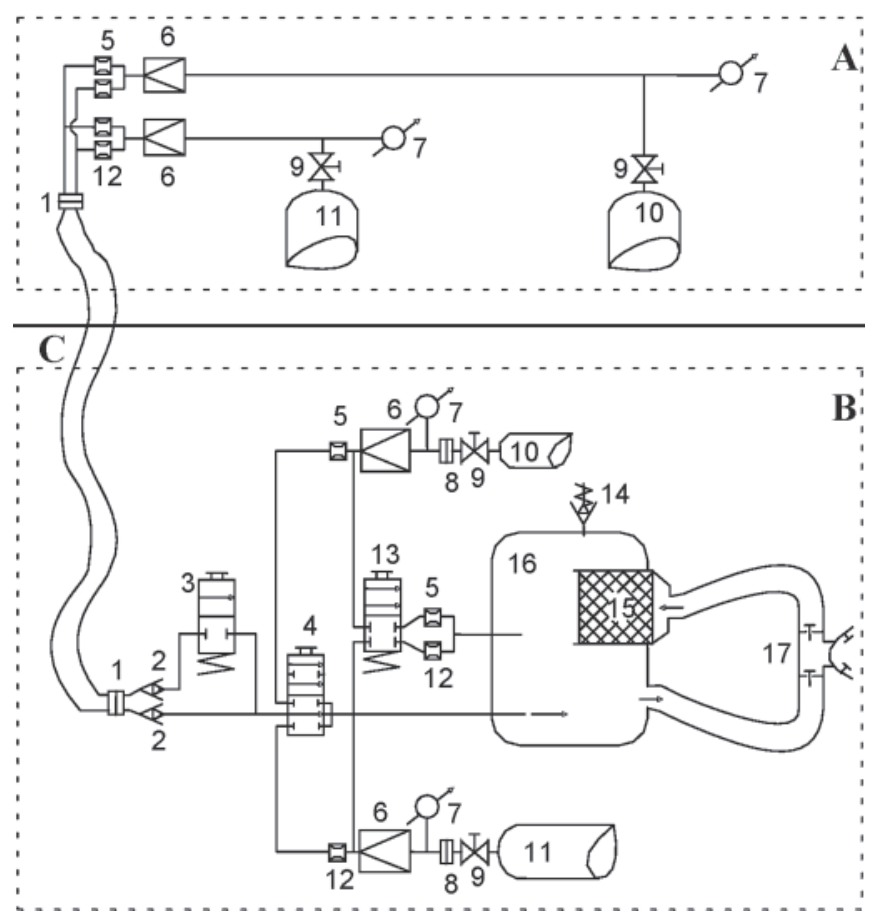

Fig. 6. One-bag version of automix-SCR. A. External supply unit of hose automix-SCR, B. SC-automix-SCR, $\boldsymbol{C}$. Group of supply wires and pipes (umbilical). 1) coupling, 2) non-return valve, 3) by-pass valve cooperating with the external supply unit $A$, 4) selector valve, 5) oxygen metering valve, 6) reducer, 7) manometer, 8) cylinder coupling, 9) cut-off valve, 10) cylinder of oxygen, 11) cylinder of inert gas, 12) metering nozzle of inert gas (e.g. helium), 13) by-passvalve cooperating with independent supply unit,

14) relief valve, 15) carbon dioxide absorbent, 16) counterlung, 17) mouthpiece device with valves and hoses 
version are equipped with installations meant for mixing breathing medium outside the system (external supply unit marked as A). The entire system producing the breathing mixture is localised on the diving station or diving bell. It may additionally be fitted with e.g. sensors of oxygen content (partial pressure). In its hose-SCR version the apparatus may consist of a combination of several units engaged in automixSCR and another premix-SCR (SC emergency supply). The SC-SCR, marked as B is showed in Fig. 6, is the automixSCR. The SC-SCR version B is made of breathing bag (bags) 16 , carbon dioxide absorbent canister 15 , gas cylinders 10 and 11, and finally of a unit generating breathing medium. The production of the breathing medium consists in mixing a stream of oxygen and a stream of inert gas. The metering of the gases is carried out by means of nozzles metering within their supercritical ranges (this issue will be discussed in Chapter 4). Appropriate reduced overpressure of gases is maintained by the pressure reducers 6 . Fullness of the cylinder is controlled by manometers 7 .

Oxygen and inert gas get mixed in the supply hose and enter counterlung 16, wherefrom via inhale hose of the mouthpiece the ready mixture is directed into the diver's lungs. The exhale is released through the mouthpiece 17 , through its valve and exhale hose, passing carbon dioxide absorbent 15 , into the counterlung. The surplus of the breathing medium escapes from the bag through the relief valve 14 into the water. Just like in the case of the apparatus discussed above, the breathing medium is also administered into the lungs of diver at a pressure which value equals the sum of ambient hydrostatic pressure of the given diving depth and the overpressure of opening the relief valve. To preliminary fill the breathing space and to wash it out with fresh breathing medium a by-pass unit 3 is used - at work with hose supply or 13 - at independent operations. Fundamental features of automix-SCR are summarized in Table 7. Example of automix-SCR discussed in Table 3 is presented in Photos $25 \div 27$.

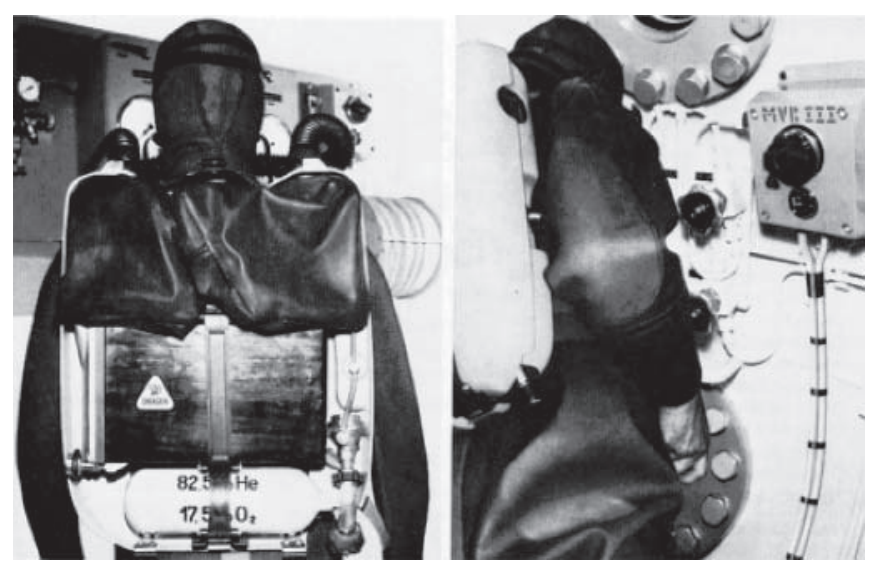

Photo 25. House-automix-SCR SMS-III type

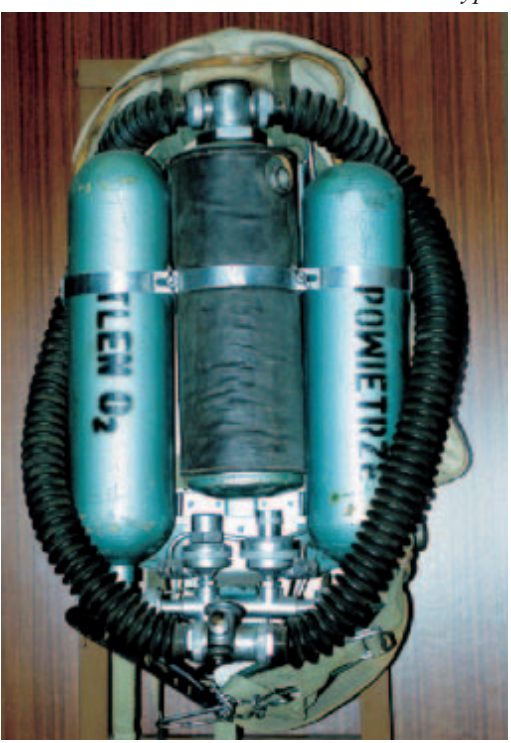

Photo 26. SC-automix- SCR APW-3 type

Table 7. Basic features of automix-SCR

Breathing apparatus of semi-closed circuit of breathing medium mixed during diving (Automix-SCR)

Automix-SCR has never been in a wide use due to the problems with their manufacturing and exploitation. It is know only in experimental or in a limited run

\begin{tabular}{|l|l|}
\hline - Homogeneity and stability of the breathing medium contained in the bag much more difficult to \\
maintain than in the designs using a premixed breathing medium. \\
- In case of apparatus producing breathing medium of a constant ratio of content between oxygen and \\
inert gas each time the composition of the breathing medium as well as the mode of metering must be \\
carefully selected sufficing only to a relatively narrow range of diving depth. \\
- Prior to each dive the apparatus must be subjected to a quite troublesome procedure of preparation and \\
checking. \\
- Despite a partial reuse of the breathing medium it gets wasted at relief valve what affects economical \\
rate of diving with breathing mixture made of expensive components. \\
- High sensitivity to dust pollution likely to chock metering nozzles. \\
- Due to a partial closure of the breathing medium circuit all these designs are less hygieninc than the \\
open circuit systems. \\
$\begin{array}{l}\text { Such as of apparatus of semi-closed circuit of premixed breathing medium, and: } \\
\text { - Potential for operating on clean gases instead of their mixtures. This allows avoid problems connected } \\
\text { with production and storing of precisely composed breathing mixtures. It enhances the economical rate } \\
\text { of exploitation of this apparatus in comparison with the diving apparatus using a premixed breathing } \\
\text { medium. } \\
\text { - A change of breathing medium for a selected range of depth involves a mere change of the metering } \\
\text { nozzles. } \\
\text { - In case of apparatus producing breathing medium of variable ratio of oxygen to inert gas the potential } \\
\text { dynamic change of the ratio between oxygen and inert gas making the breathing medium according to } \\
\text { the depth of diving. }\end{array}$
\end{tabular}




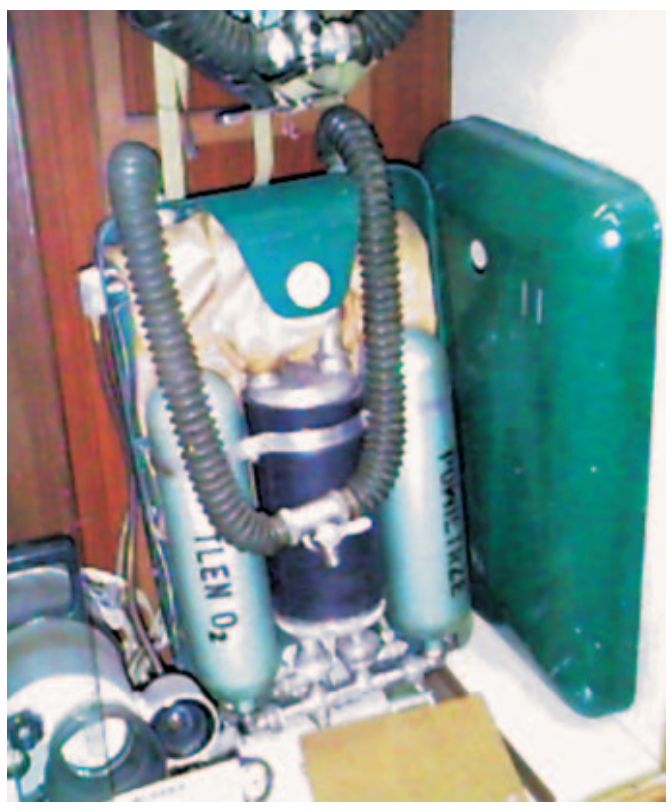

Photo 27. SC-automix-SCR APW-6 type

\section{CLOSED CIRCUIT BREATHING APPARATUS (CCR)}

The designs of closed circuit breathing apparatus (CCR) can be divided into:

- oxygen CCR (oxy-CCR)

- breathing mixtures CCR (mix-CCR).

\section{Oxygen CCR}

Oxygen is the most often specified group of the closed circuit breathing medium [7]. In oxy- CCR the breathing cycle is as follows: oxygen is inhaled from the breathing space of CCR. As it is exhaled, the gas passes through canister with carbon dioxide absorber to the breathing space. Oxygen consumption during diving is not large, not the diving depth affected but dependent only upon the work performed.

When compared to open circuit UBA, oxy-CCR doesn't require large supply of the breathing gas and offer an enrange action radius range. Therefore, construction of oxy-CCR enables extended operating duration, however due to oxygen toxicity it can be used only at the shallow depths. As there is no need for a periodical release of the breathing medium, there are no escaping bubbles to the water and oxy-CCR can be used for special diving covered warfare. During normal work that system requires only periodical washout of the breathing space to eliminate accumulating contaminants and wash out of nitrogen that saturates human body under normal conditions. There is also need for release of the breathing medium excess during ascend of the diver. Due to oxygen toxicity, an oxygen dive is limited by the depth and exposure time. Moreover, an oxygen diver should satisfy special physical and psychical predisposition. For these reasons an oxygen dive is prohibited in many countries, however, is possible to carry out in civil underwater operations.

Oxy-CCR constructions have been developed in two main directions. The first is an improvement of traditional construction of the Fleuss CCR. It consists of the breathing bag connected with carbon dioxide absorbent canister. The canister may be filled with carbon dioxide absorbent (different forms of soda lime are most often used) or with various oxygen generating masses (sodium, potassium or lithium superoxides). These apparatuses may have manual or constant oxygen metering system (the latter aided with manual or automatic periodical adding of oxygen). Example of oxy-UBA is presented in Fig. 7. Improvement of this oxy-CCR design consists in the use of patents leading to its better tactical-technical properties. Elimination of buoayancy change effects due to breathing rate and the changes in the depth of dive, application of the constructional solutions leading to reduced breathing resistance, application of compact designs, elimination of the magnetic field generated by the oxy-CCR, elimination of the noise generated during breathing and oxy-CCR work, application of the oxy-CCR equipment that enables camouflage during transport and covered storage, application of constructions that not require special tools at daily servicing, corrosion and trying conditions resistant materials, water temperature change resistant constructional and exploitation materials, maximisation of the apparatus mass to its action radius range, application of streamline shapes of low resistance during swimming etc.

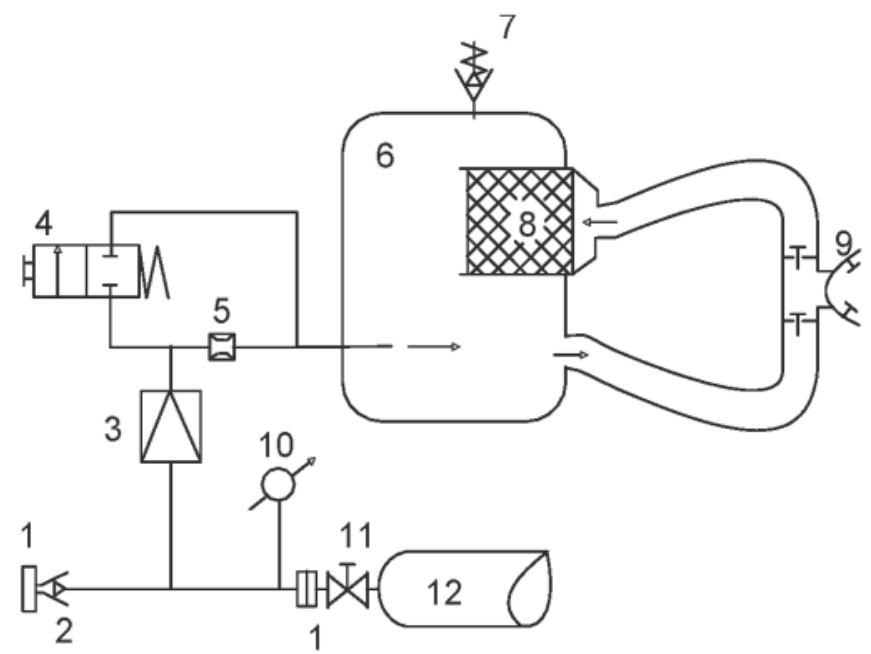

Fig. 7. SC-CCR of the constant oxygen metering. 1) joint, 2) non-return valve, 3) reducer, 4) by pass valve, 5) oxygen metering nozzle, 6) the breathing bag, 7) relief valve, 8) cylinder coupling, 9) mouthpiece assembly with valves and hoses, 10) manometer, 11) cut-off valve, 12) oxygen cylinder

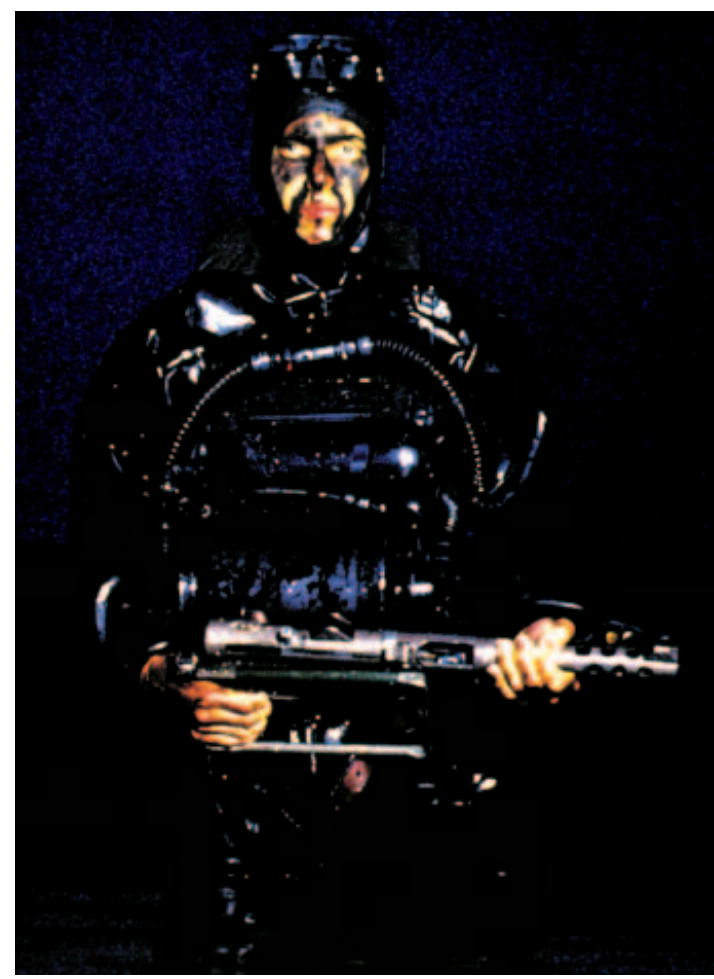

Photo 28. Oxy-CCR AGA-Oxydive type 

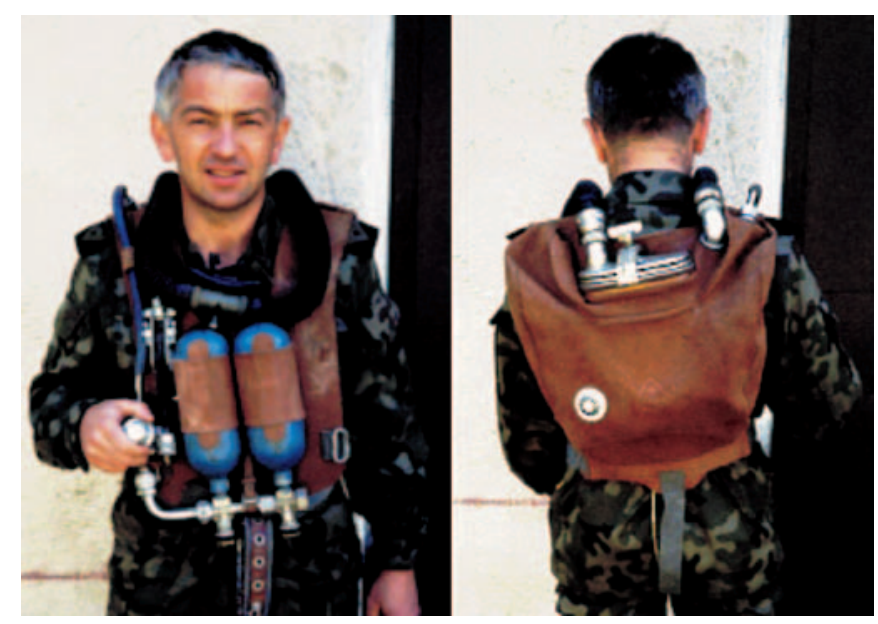

Photo 29. Oxy-CCR LT II type

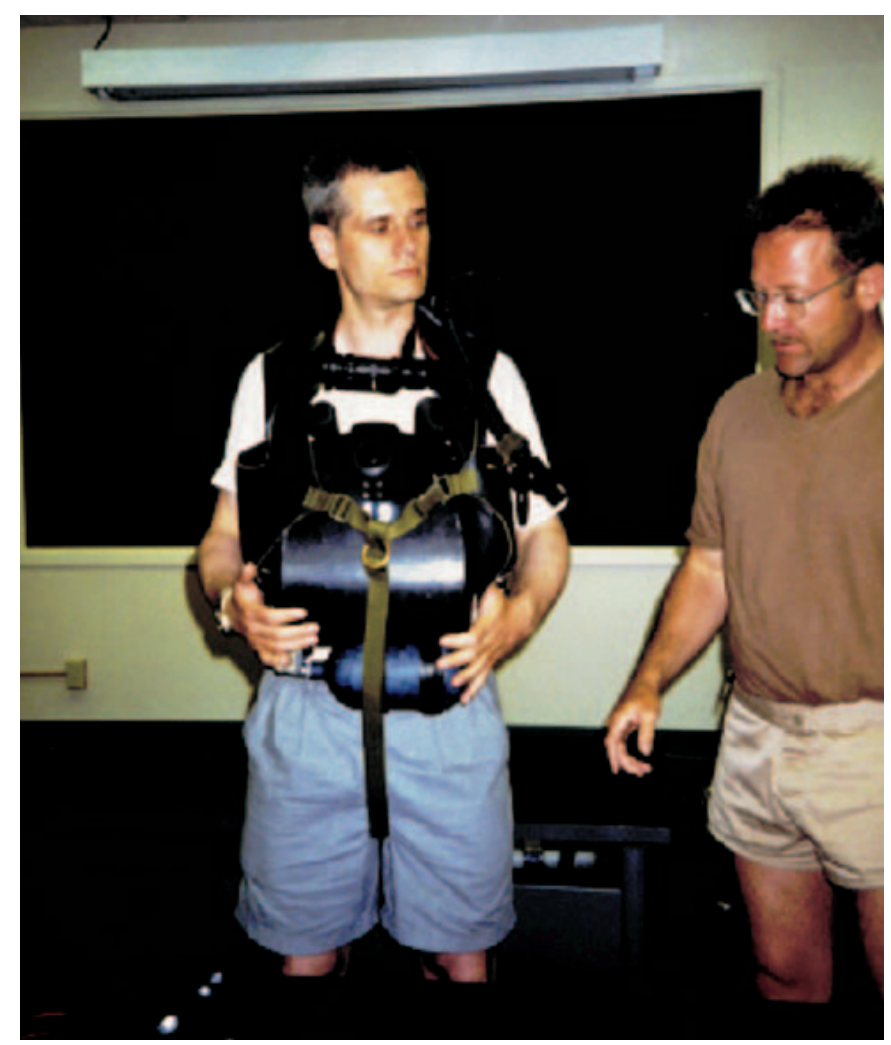

Photo 30. The author and oxy-CCR LAR V type

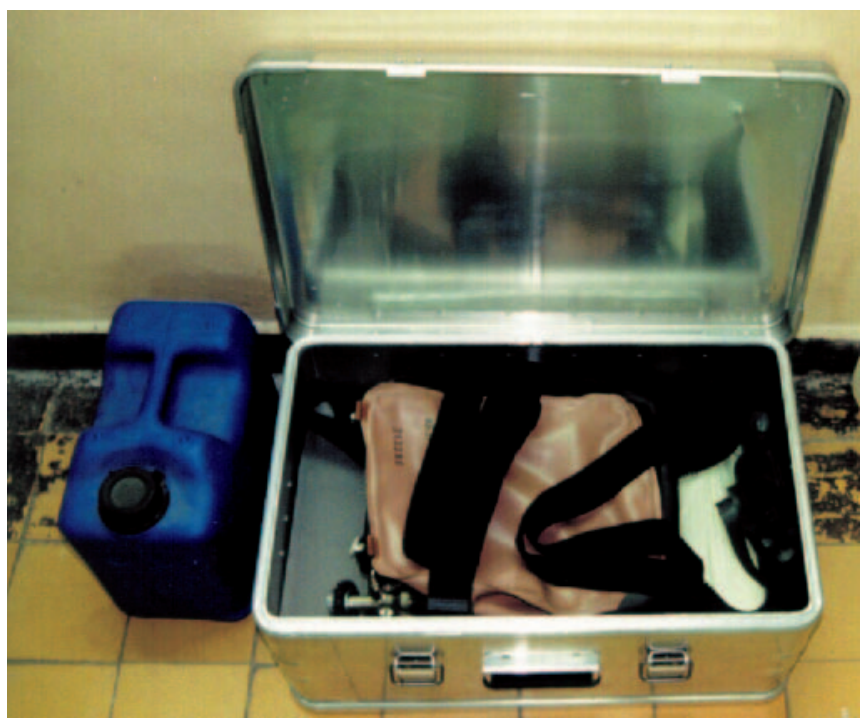

Photo 31. Oxy-CCR LAR VII type

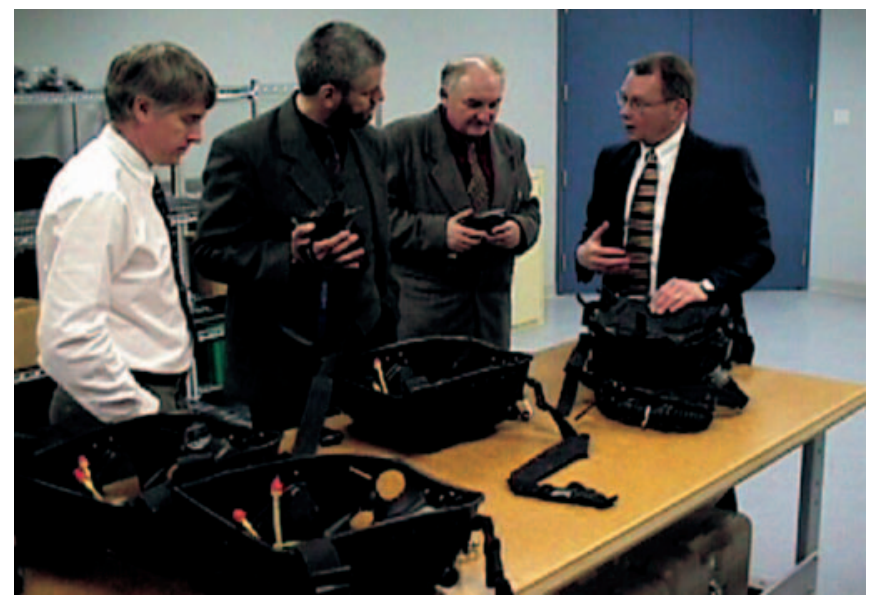

Photo 32. The author and oxy-CCR S-10 type

Swedish oxy-CCR AGA-Oxydive type (Photo 28), German oxy-CCR LT II type (Photo 29) or later version LAR V (Photo 30) and LAR VI (Photo. 31), or Canadian S-10 (Photo 32) represent this group of oxy-CCR.

Another group consists of oxy-CCRs, where instead of the breathing bag a large rubber diaphragm is used, arranged on the top of the shallow box, with the lever of by-pass valve on its bottom. If oxygen volume in the breathing space falls below a certain established minimum, the diaphragm will press the lever triggering oxygen by-pass valve. The diaphragm is strapped with the limiters adjusting maximum breathing space volume to the diver's preferences and mass of his equipment. Solutions of oxy-CCR are employed in American Cobra (Photo 33) or French OXY-NG (Photo 34).

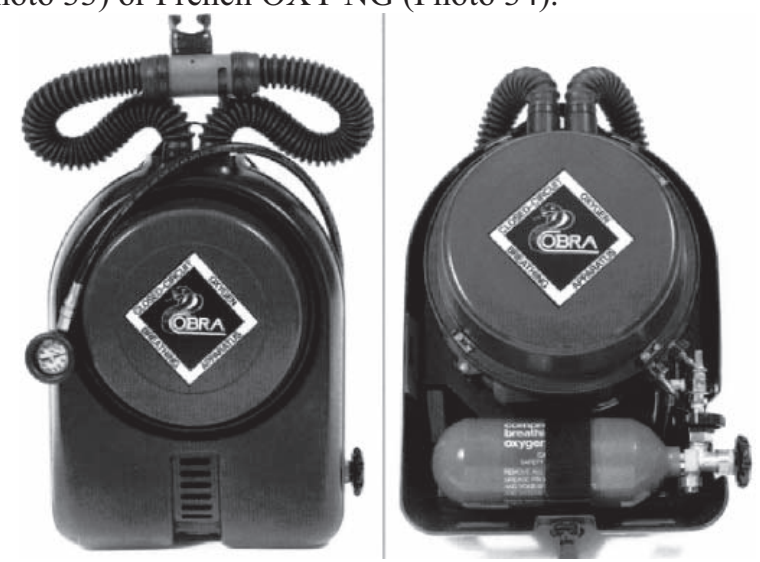

Photo 33. Oxy-CCR Cobra type
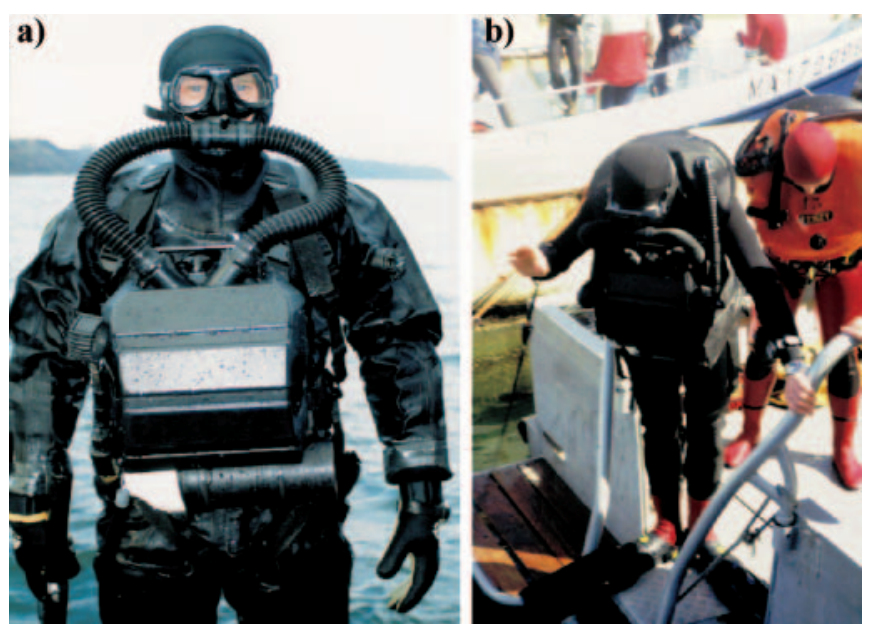

Photo 34. oxy-CCR Oxy-NG type. a) during sea tests (the own photo), b) the author during trials in the harbour basin of Marseill 


\section{$\operatorname{Mix}-\boldsymbol{C C R}$}

Closed-circuit gas mixture UBA (mix-CCR) can be groped as follows:

* small circuit mix-CCR

* increased (enlarged) circuit d mix-CCR

* large circuit CCR.

Small circuit mix-CCR are called the SC-mix-CCR, e.g.: Mk 15/16 - Photo 35. increased (enlarged) circuit mix-CCR denotes a circuit between the apparatus and the diving bell (or other submersibles) equipped with measuring instruments, systems of regeneration and enrichment the breathing gas with oxygen and so on, e.g.: Dolphin 7, Photo 36. A large circuit of mix-CCR is the circuit between the surface (via e.g.: the diving bell) and the diver. The measuring equipment, systems of regeneration and enrichment the breathing gas with oxygen are placed on the surface, e.g.: CCBS 450 with the surface system GAK 600, the diver's equipment and the main table of the system (Photo 37).
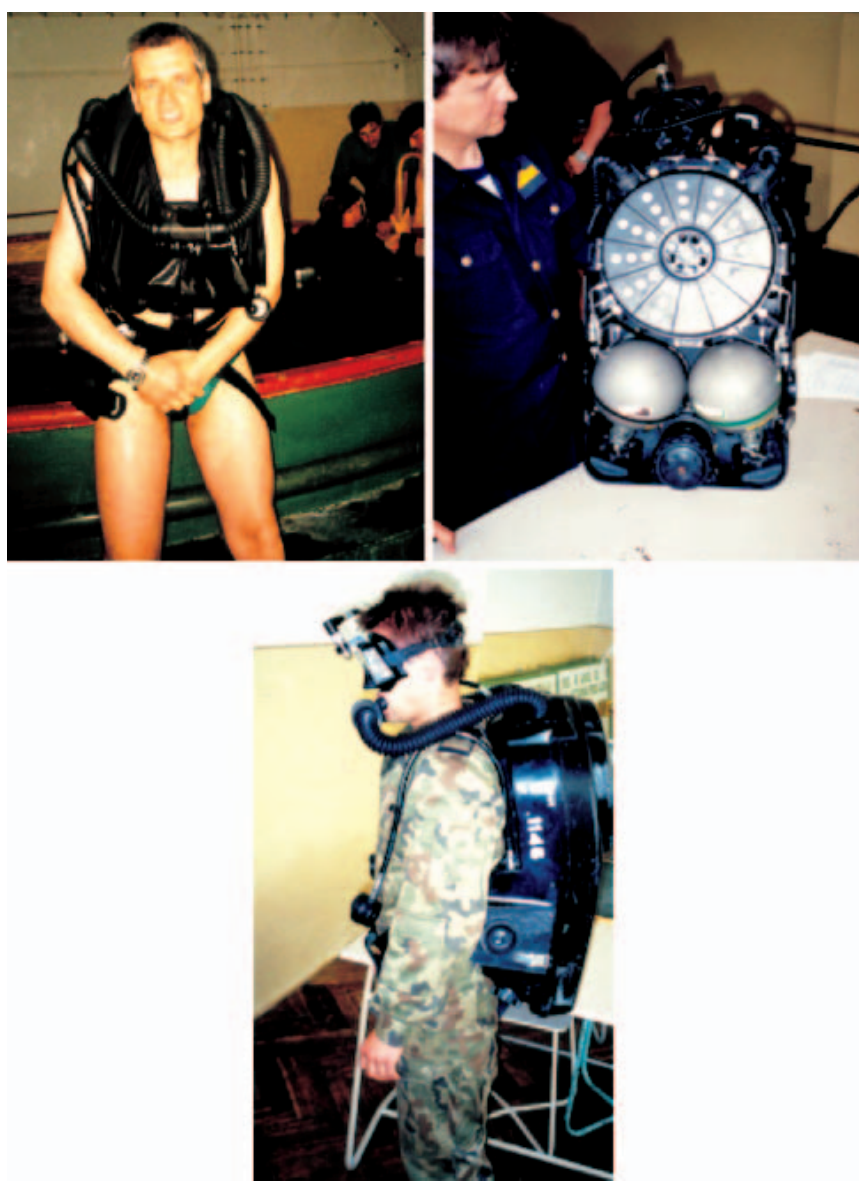

Photo 35. The author before diving with use Mk-15/16 and views of SC-mix-CCR Mk-15/16 type

General principle of the SC- mix-CCR operation is presented in Fig. 8. Elektrolung, popular name of this design comes from the apparatus manufactured by Oceanic Equipment Co. (Photo 38).

The breathing bag (Fig. 8) together with the carbon dioxide absorbent canister is connected with the mouthpiece assembly by means of the breathing hoses. The breathing medium circulates within as with the direction arrows in the Fig. 8. Inhale and exhale valves ensure one-way direction. These constructional junctions operate in exactly the same way as SCRs discussed above. From the cylinder 1 via cut-off valve 2 inert gas flows into the breathing bag, passing on its way:
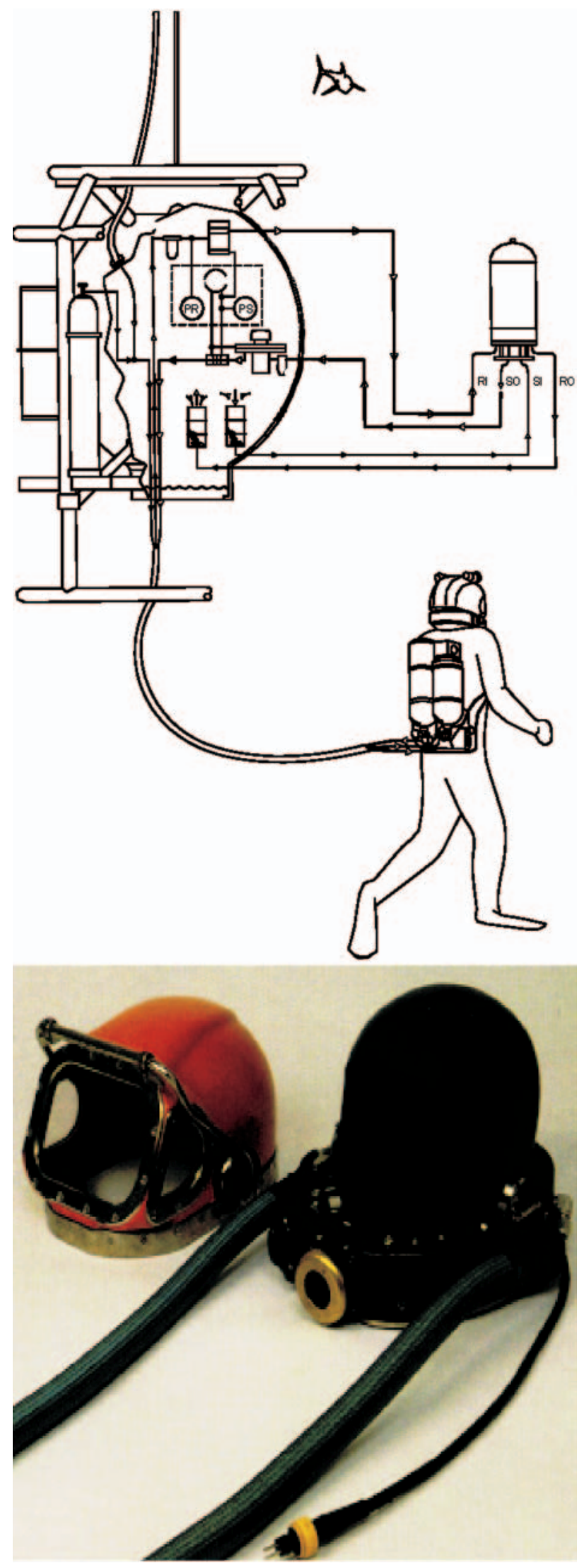

Photo 36. The diving mix-CCR system and diving helmet Dolphin 7 type

manometric pressure control 4, and the automatic assembly allowing for ambient hydrostatic pressure at the depth of diving 5. Oxygen from oxygen cylinder 16 runs through cut-off valve 2 , manometric control 4, through the oxygen reducer 15 and flow controlling valve 13 into the breathing bag. The oxygen sensor 9 placed in the breathing bag, constantly measures the oxygen partial pressure. The signal is simultaneously displayed 

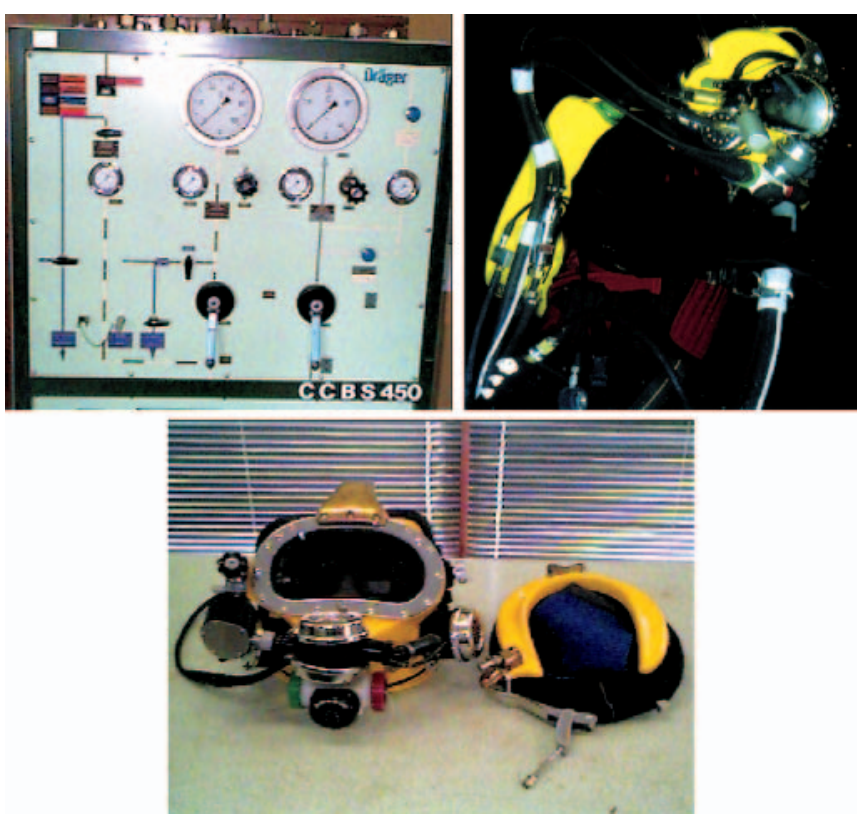

Photo 37. Main board and the diver's hose-mix-CCR system CCBS type
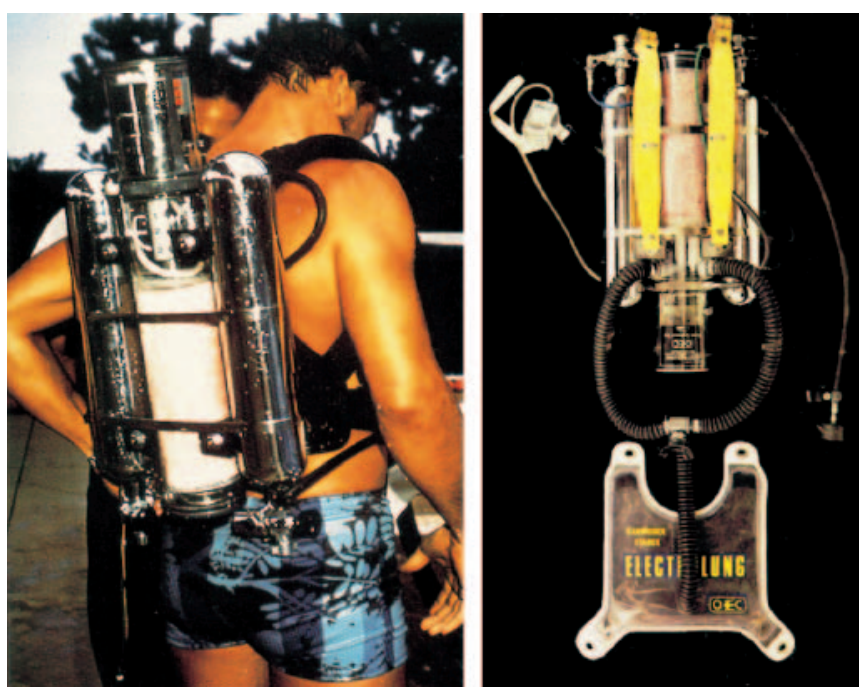

Photo 38. Elektrolung SC-mix-CCR manufactured by Oceanic Equipment Co [1]

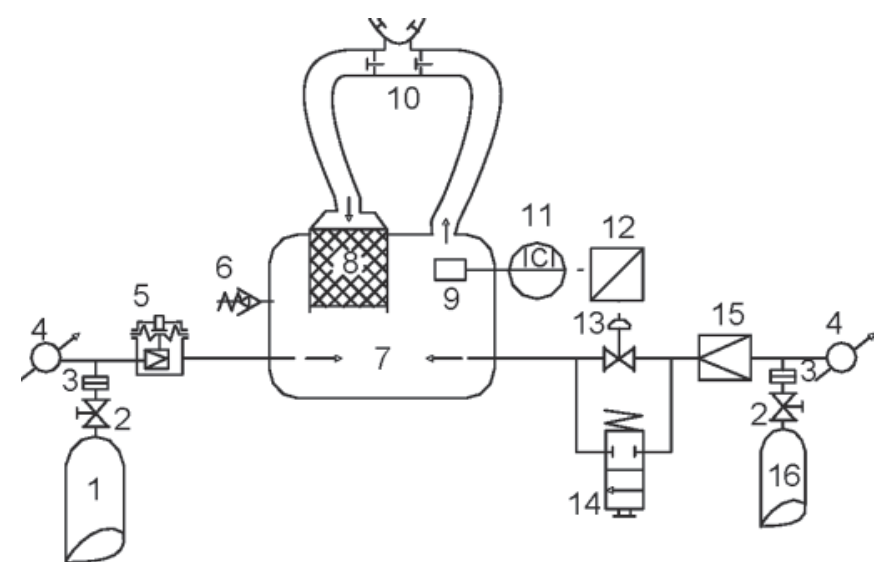

Fig. 8. SC-mix-CCR. 1) inert gas cylinder (e.g. helium), 2) cut-off valve, 3) coupling, 4) manometer, 5) reduction unit maintaining the filling of the breathing bag at the demanded level, 6) relief valve, 7) breathing bag, 8) carbon dioxide absorbent, 9) sensor of oxygen partial pressure,

10) mouthpiece device with valves and hoses, 11) measuring-controlling unit of oxygen partial pressure, 12) converter of electric signal into pressure response, 13) valve with pneumatic servo, 14) oxygen by-pass valve, 15) oxygen reducer, 16) oxygen cylinder on the diver's control desk and is transmitted to current-pressure transducer 12. The transducer uses the oxygen line to perform supply the executive element regulating opening of the valve 13. If the oxygen partial pressure is too small, the valve 13 will be opened by the executive pneumatic element. Additional bypass valve 14 is used for a preliminary filling of the breathing bag and its washout during oxygen compression. There were three sensors instead one of the oxygen partial pressure applied in this type of CCR (similar to Mk15/16 mix-CCR). The indications of each one were displayed on the diver's control board. Additional sensors not shown in Fig. 8 served as also as sensors of low or high partial pressure signal in the breathing bag. They were specifically calibrated so that their sensitivity should be maximal at the established maximum oxygen partial pressure (IIAH) and the established minimum oxygen partial pressure (IIAL). They signalled any exceeding of these values. Apart from measuring and transmitting the signal on the diver's board, main sensor 9 controlled opening of the oxygen valve.

Enlarged and large circuit mix-CCR are complete systems supporting dives. An example of such a system is presented in Fig. 9. The UBA (the diver's helmet) is equipped with a switch of operation mode that can be set on operation either in closed or open system. It can be also set in the position of the SC-mix-CCR (bail-out UBA) provided the system has one. In case of the system failure, bail-out UBA cannot be used if the diver switch on the diver's helmet emergency valve to the open circuit system, being supplied then with emergency breathing medium.

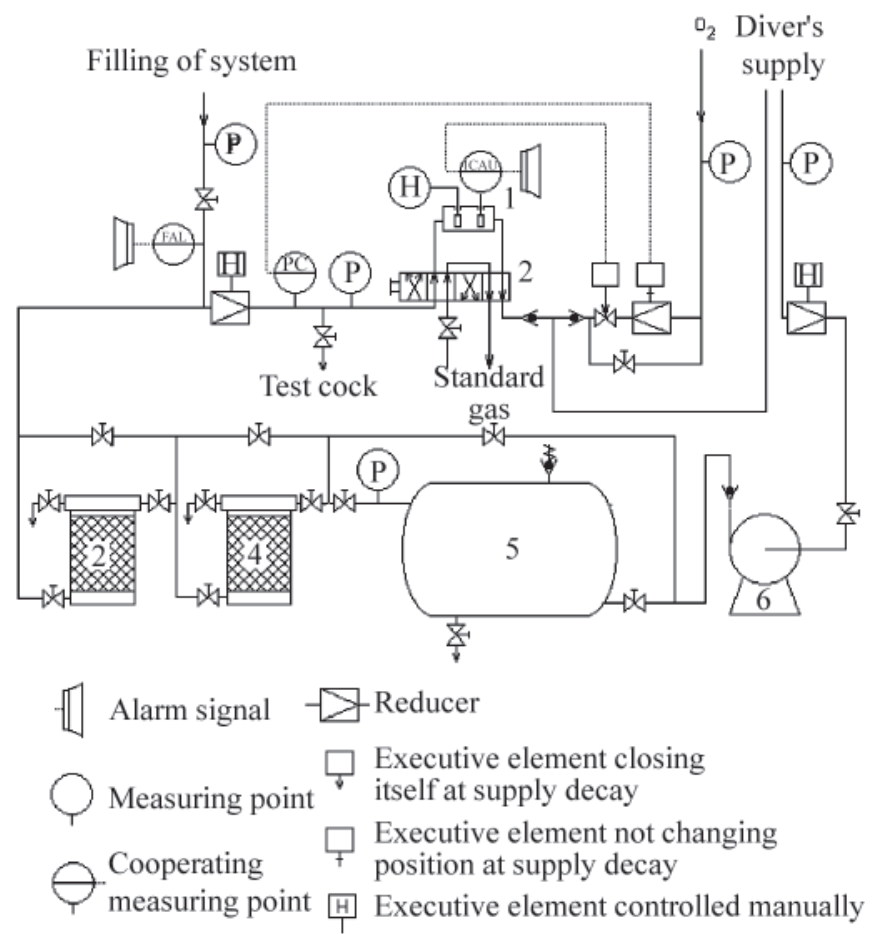

Fig. 9. Supply unit of large closed circuit of breathing medium mix-CCR. 1) unit for measuring oxygen partial pressure and breathing medium humidity, 2) group of selecting valves for control of measuring unit in operation, 3) drier, 4) carbon dioxide absorbent, 5) storage reservoir, 6) compressor unit. $\boldsymbol{P}$ - point of measuring pressure, $\boldsymbol{P C}$-point of measuring pressure and automatic control, $\boldsymbol{H}$-measuring point of humidity or manual control, ICAU - measuring of sensor current and automatic control with a signalling of low and high level, $\boldsymbol{F A L}$ - flow indicator

Breathing medium is stored in the surface store-room or in gas cylinders placed on the diving bell. The breathing medium circuit exemplary system (Fig. 10, PMR 1/2008) is forced with pump 6 . The pump sucks the exhaled gas through manually operated reducer that is being set on sucking. Then gas 


\section{Closed-circuit breathing gas mix underwater breathing apparatus (Mix-CCR)}

Mix-CCR can be classified in two groups that differ with the breathing medium applied. There are two types oxy-CCR and mix-CCR. Oxy-CCR is primarily used for military purposes. Mix-CCR is mostly used in large (or enlarged) circuit version in saturation diving operations.

\begin{tabular}{|l|l|}
\hline - Large circuit mix-CCR requires an extensive and technically complicated system of gas-supply operated \\
by highly skilled personnel. \\
- Small circuit mix-CCR is very complicated construction and requires expert personnel. Due to the lack of \\
good oxygen partial pressure sensors mix-CCR can be unreliable. \\
- Oxy-CCR should be used by specially trained divers of special presidposition due to the possibility of \\
carbon dioxide poisoning. \\
- Due to closure of the breathing gas circuit in all CCR type constructions accumulation of contaminants \\
can occur.
\end{tabular}

is pumped to the system, where from after purification is repeatedly pumped to the diver through the pump reducer (supply reducer). The settings of the reducers on the sucking and pumping line are connected with each other and depend upon the range of the diving depth and ventilation rate required. Together with the valves of the mouthpiece assembly they ensure a proper circulation of the breathing medium. They prevent the pump from sucking out the whole breathing gas form the circuit and the breathing gas being not all suddenly pumped into the diver's helmet, at too large pressure. The breathing medium when sucked by the pump passes through the storage reservoir 5 , carbon dioxide 4 and dryer 3 and earlier mentioned reducer to the measurement chamber1. In the measurement chamber arranged on the gas line the breathing medium humidity is measured $(\mathrm{H})$ and the oxygen contents (ICAU). The oxygen by-pass valve is controlled by the measurement. In case of failure the oxygen adding can be manually operated and the supply unit is fit to work in a mode of emergency supply of the breathing medium-through the valve that enables to fill the system. In this situation gas exhaled by the diver is directed into the water (open circuit work- after the appropriate switch of the valves in the diver's helmet). The rate of breathing gas dehumidification is operated manually by the dyer by-pass valve. Appropriate positioning of this valve with the dryer inlet valve separates stream of breathing gas that enables control of flowing breathing gas dehumidification. The system must offer a possibility of calibrating its measuring instruments with standard gases (valve 2) and periodical breathing gas sampling (test cock) for gas analysis. Characteristic of closed circuit apparatus is given in Table 8 .

\section{CONCLUSIONS}

O Beyond any doubt air-UBA are the most often used construction among other that have been described earlier. Intensive development of these constructions has led to highly reliable UBA despite its relative complexity.

Other described types of UBA exemplify the elementary production of specialised companies. Some types of UBA have never been implemented or were manufactured occasionally and are not in common use. Undoubtedly, except air-UBA, constant metering premix-SCR (used during dives beyond saturation zone, especially dedicated for $\mathrm{M} \mid \mathrm{CM}$ divers), mix-CCR (used during saturation deepdiving), and oxy-CCR (military application) are the most often used UBA.
O Despite of their unquestionable disadvantages premixSCR are relatively simple designs. It makes that SCR are technically reliable. Recently great interest is focused on special construction diving apparatuses. Premix-SCR is employed for independent deep diving operations. "Technical diving" is the special hazardous kind of diving that attracts from all over the world the wide groups of divers looking for strong sensations.

\section{BIBLIOGRAPHY}

1. Bachrach A.J., Desiderati B.M., Matzen M.M.: A pictorial history of diving. Best Publishing Co. 1988

2. Clarke D.W.: The history of breathing apparatus and current state of the art $\ddagger$ z: $\$$ Lung and physiology and divers breathing apparatus. Proceedings from the International Workshop Ballater, Scotland, 1 $\div 4$ Nov. 1991: Department of Biomedical Sciences Marshal College Aberdeen 1992

3. Diving Manual: Ministry of Defence (Navy), B.R.2805 (Army Code No 61231) March 1982

4. Gussman J.: The man is getting depths. Wydawnictwo Morskie Gdańsk 1984

5. Mer \& Océan - Spécial Cousteau 1997

6. Underwater works: Wydawnictwo Morskie Gdańsk 1971

7. Przylipiak M., Torbus J.: The equipment and diving works guide. WMON Warszawa 1981

8. Rawlis J.: The history of commercial, military and sport diving. Trans. IMarE 101(1989) $161 \div 170$

9. The five methods for professional diving. Announcement Drägerwerk AG Lübeck (Oct.1987)

10.Shilling C. W., Werts M. F., Schandelmeier N. R.: The underwater handbook. Plenum Press New York and London

11. US Navy diving manual. Best Publishing Co. Carson California 1980

12.US Navy diving manual (revision 3). The Direction of Commander, Naval Sea Systems Command 1993

\section{CONTACT WITH THE AUTHOR}

Ryszard Kłos, Assoc. Prof.

Department of Diving Technology and Underwater Activities

Polish Naval Academy

Śmidowicza 69

81-103 Gdynia POLAND

e-mail: skrzyn@wp.pl 